ALINE BEATRIZ HENRIQUES OLIVEIRA DIAS

DESJUDICIALIZAÇÃO DE CONFLITOS REPETITIVOS ENTRE CONSUMIDORES E BANCOS: UMA PROPOSTA

\author{
Dissertação de Mestrado \\ Orientador: Professor Doutor Carlos Alberto Carmona
}

UNIVERSIDADE DE SÃO PAULO

FACULDADE DE DIREITO

São Paulo - SP

2017 



\title{
DESJUDICIALIZAÇÃO DE CONFLITOS REPETITIVOS ENTRE CONSUMIDORES E BANCOS: UMA PROPOSTA
}

\begin{abstract}
Dissertação apresentada à Banca Examinadora do Programa de Pós-Graduação Stricto Sensu da Faculdade de Direito da Universidade São Paulo, como requisito parcial para obtenção do título de Mestre em Direito, na área de concentração Direito Processual, sob a orientação do Prof. Carlos Alberto Carmona.
\end{abstract}

\section{UNIVERSIDADE DE SÃO PAULO \\ FACULDADE DE DIREITO}

São Paulo - SP 
Autorizo a reprodução e divulgação total ou parcial deste trabalho, por qualquer meio convencional ou eletrônico, para fins de estudo e pesquisa, desde que citada a fonte.

Catalogação na publicação

Serviço de Biblioteca e Documentação

Faculdade de Direito da Universidade de São Paulo

Dias, Aline Beatriz Henriques Oliveira.

Desjudicialização de conflitos repetitivos entre consumidores e bancos: uma proposta / Aline Beatriz Henriques Oliveira Dias ; orientador, Carlos Alberto Carmona. -- São Paulo, 2017 $237 \mathrm{p}$.

Dissertação (Mestrado - Programa de Pós-Gradução em Direito Processual) - Faculdade de Direito, Universidade São Paulo, 2017

Versão original

1. Direito. 2. Direito Processual Civil 3. Disputas 4. Consumidor 5. Banco.

I. Dias, Aline Beatriz Henriques Oliveira II. Carmona, Carlos Alberto, orient. II. Título 


\section{TERMO DE APROVAÇÃO}

Nome: DIAS, Aline Beatriz Henriques Oliveira Dias.

Título: Desjudicialização de conflitos repetitivos entre consumidores e bancos: uma proposta.

Dissertação apresentada à Banca Examinadora de Pós-Graduação em Direito, da Faculdade de Direito da Universidade de São Paulo, como exigência parcial para a obtenção do título de Mestre em Direito, na área de concentração Direito Processual, sob a orientação do Professor Doutor Carlos Alberto Carmona.

Data de aprovação:

Banca examinadora

Prof. Dr. Instituição:

Julgamento: Assinatura:

Prof. Dr. Instituição:

Julgamento: Assinatura:

Prof. Dr. Instituição:

Julgamento: Assinatura: 
À memória de Olívio José de Oliveira. 


\section{AGRADECIMENTOS}

Por muitas vezes, o tempo que dediquei a esta dissertação ocasionou, ao menos na minha visão, que eu não fosse uma boa colega de trabalho, boa amiga, boa noiva ou boa filha. É por esse motivo, e pelos inúmeros abraços que recebi nesses últimos tempos, que escrevo aqui meus mais sinceros agradecimentos.

À minha querida família (Maju, Guto, Dona Dora, Brenda, Camila, Ana Paula, Ana Lu, Gabriel, tio Mario, tia Esme, Juju e Mariozinho), o agradecimento por sempre terem me dado o maior amor do mundo.

Ao amor da minha vida, Ivan Iegoroff de Mattos, em celebração da primeira década de nossa vida juntos, e à amada família Matos e Mattos, transmito meu imenso agradecimento por cada minuto de apoio incondicional.

Esta dissertação também é dedicada:

Aos melhores irmãos que a vida poderia me dar: Ricardo Dalmaso Marques e Mayara Lazzaro Oksman.

Aos meus queridos amigos: Leonardo Ramos Nogueira, Caio Carvalho Rossetti, Mariana Cordon Martines, Isabela de Almeida Castro Fonseca, Juliana Capano Sanchez, Nathalia Farias Costa, Paula Brazão Gerencer, Daniel Tavela, Ligia Ferreira Novais de Oliveira, Wilson Luís Vollet Filho, Gabriel Teodoro de Oliveira, Mayara Roth Isfer Osna, Ivo de Paula Medaglia, Heloize Marçal Salomé Medaglia, Isabela Moreira de Andrade Vosgerau, Adriano Gomes, Caroline Cavassin Klamas, Bruna Alcino Marcondes da Silveira, Douglas Depieri Catarucci, Eva Ricciardi de Paula, Kauê Cardoso de Oliveira e Lucas Alves Evaristo dos Santos.

Ao incrível time de advogados e demais integrantes do escritório Muriel Medici Franco Advogados, em especial à equipe de arbitragem: Ana Paula Barbosa Mageste, Antonio Henrique Monteiro, Giovanny Ferreira Russo, Marina Maciel de Barros, Marina Paranaíba Mendes, acompanhados dos meus eternos professores Thiago Marinho Nunes, Fernando Medici Junior e Marcelo Antonio Muriel.

Ao mais integrado e competente time de estudantes que poderia estar ao meu lado: Ana Flávia Paiffer dos Santos, Arthur Ferreira Brasil e Fernanda Cominato Nemr. 
Aos integrantes do Grupo de Estudos em Arbitragem da Universidade Presbiteriana Mackenzie (GEAMack), com os quais aprendi muito mais do que eu poderia imaginar.

Por fim, como não poderia deixar de ser, aos importantes mestres que mais me inspiram na área acadêmica: querido orientador Carlos Alberto Carmona, Susana Henriques da Costa e estimados amigos Carlos Stefen Elias, José Augusto Ferreira Bittencourt, Mariana Capela Lombardi, Ricardo Aprigliano e Ronaldo Vasconcelos. 


\section{RESUMO}

DIAS, Aline Beatriz Henriques Oliveira. Desjudicialização de Conflitos Repetitivos entre Consumidores e Bancos: uma proposta. 237p. Dissertação (Mestrado em Direito) Faculdade de Direito, Universidade de São Paulo, São Paulo, 2017.

A evolução do conceito de acesso à justiça permite o desenvolvimento da ideia de que a concretização da justiça não deve ser vista como uma responsabilidade exclusiva do Estado. O Poder Judiciário possui algumas limitações incompatíveis com a garantia de amplo acesso à justiça garantida pela Constituição Federal. Dada essa problemática, defende-se que especialmente as empresas envolvidas em altos números de litígios no país (os grandes litigantes) devem abrir portas para que a solução dos conflitos oriundos de sua atividade empresarial não dependa da atividade do Estado. Para ilustrar o tema, foi escolhido o caso dos conflitos entre consumidores e bancos. O estudo busca propor ideias para a implementação de um novo método privado para solução desses conflitos no Brasil, considerando a técnica do Desenho de Sistema de Disputa. Esse novo método, inspirado no Ombudsman de Bancos estrangeiro, deve ser financiado por recursos dos próprios bancos e deve resultar em determinação vinculante ao banco quando assim desejado pelo consumidor.

Palavras-chave: Acesso à justiça. Poder Judiciário. Banco. Instituição Financeira. Consumidor. Desenho de Sistema de Disputa. Ombudsman de Bancos. 



\begin{abstract}
DIAS, Aline Beatriz Henriques Oliveira. Desjudicialização de Conflitos Repetitivos entre Consumidores e Bancos: uma proposta. 237p. Dissertação (Mestrado em Direito) Faculdade de Direito, Universidade de São Paulo, São Paulo, 2017.

The concept of access to justice evolved to allow the idea that the achievement of justice is not a sole responsibility of the Government. Brazilian Courts coexist with certain limitations incompatible with the broad access to justice guaranteed by the Federal Constitution. In this context, companies involved in large numbers of judicial cases (the repeat players) should seek for methods to avoid litigation, so that the resolution of conflicts arising from their business activity does not depend exclusively on the Courts. To illustrate that, this study examines the case of conflicts between consumers and banks. The study aims to propose guidelines for the implementation of a new private method to solve these conflicts in Brazil, considering the technique of Dispute Systems Design. This new private method is inspired by the foreign mechanism of the Banking Ombudsman, in proceedings financed by banks' resources and resulting in binding determination to the bank when so desired by the consumer.
\end{abstract}

Keywords: Access to justice. Judicial Courts. Bank. Financial Institution. Consumer. Dispute Systems Design. Banking Ombudsman. 



\section{SUMÁRIO}

1. INTRODUÇÃO: NOVOS RUMOS DA RELAÇÃO ENTRE FORNECEDORES E CONSUMIDORES

2. CONTEXTO HISTÓRICO: JUDICIALIZAÇÃO E MASSIFICAÇÃO DE CONFLITOS

2.1. Acesso ao Poder Judiciário versus acesso à justiça .

2.2. O crescimento da população consumidora e os seus impactos na judicialização de conflitos

3. TENDÊNCIA ATUAL: ADEQUAÇÃO DO PROCEDIMENTO À DEMANDA E DESJUDICIALIZAÇÃO.

4. "JUSTIÇA É OBRA COLETIVA": OS BANCOS COMO CORRESPONSÁVEIS PELA PACIFICAÇÃO DE CONFLITOS DE CONSUMO 45

4.1. Os bancos como grandes litigantes 45

4.2. Canais para tratamento de reclamações dos consumidores 57

4.2.1. Canais internos existentes no Brasil 58

4.2.1.1. Atendimento pessoal na agência bancária 59

4.2.1.2. Serviço de Atendimento ao Consumidor (SAC) 60

4.2.1.3. Ouvidoria - Resolução CMN nº 4.433/2015 65

4.2.2. O esquema de Ombudsman Bancário 69

4.3. Filtros de demandas recentemente desenvolvidos no Brasil. 79

4.3.1. 16 de junho de 2014: Termo de cooperação técnica entre o Conselho Nacional de Justiça (CNJ) e a Federação Brasileira de Bancos (Febraban) ..... 82

4.3.2. $1^{\circ}$ de julho de 2014: Criação da Plataforma Consumidor.gov 84

4.3.3. 2 de julho de 2014: Estratégia Nacional de Não Judicialização 87 
4.3.4. 11 de novembro de 2014: Pacto de Mediação coordenado pela Federação e pelo Centro das Indústrias do Estado de São Paulo .89

4.3.5. 25 de fevereiro de 2015: Programa "Empresa Amiga da Justiça" no Tribunal de Justiça do Estado de São Paulo .92

4.3.6. 12 e 13 de setembro de 2016: I Seminário Ombudsman como Forma de Desjudicialização dos Conflitos na Relação de Consumo .94

5. PROPOSTA: APRIMORAMENTO DAS FORMAS PARA SOLUÇÃO DE DISPUTAS ENTRE CONSUMIDORES E BANCOS 97

5.1. O papel do DSD - Desenho de Sistema de Disputa. .98

5.2. Importância de aplicação do DSD na relação banco-cliente 103

5.3. Natureza do procedimento apresentado pela Proposta FGV-STJ

5.4. Proposições para implementação de um Ombudsman Bancário no Brasil.....115

5.4.1. Elementos basilares

5.4.1.1. Compromisso dos bancos 118

5.4.1.2. Fiscalização e Gestão 122

5.4.1.3. Financiamento do Serviço. 123

5.4.1.4. Bancos e consumidores sujeitos ao Serviço 128

5.4.1.5. Disputas sujeitas ao Serviço 129

5.4.1.5.1. Inadimissibilidade imediata da reclamação...129

5.4.1.5.2. Necessidade de reclamação prévia ao banco. 130

5.4.1.5.3. Valor da disputa 132

5.4.1.5.4. Matéria em disputa 134

5.4.1.6. Critérios para seleção do Ombudsman 139 
5.4.1.7. Funções do Ombudsman.............................................. 144

5.4.1.8. Outras bases do Serviço de Ombudsman....................... 148

5.4.1.8.1. Igualdade substancial ................................. 148

5.4.1.8.2. Celeridade.................................................. 150

5.4.1.8.3. Sigilo, Publicidade e Privacidade .................. 152

5.4.1.8.4. Desnecessidade de advogados....................... 156

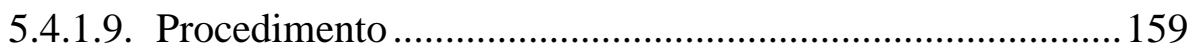

5.4.1.10.Fundamentos da determinação do Ombudsman .................. 166

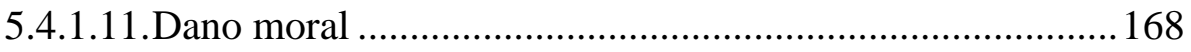

5.4.1.12.Vinculação das partes à determinação................................. 171

5.4.1.13. Não cumprimento voluntário da determinação ................... 175

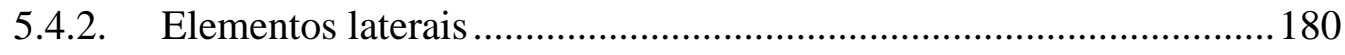

5.4.2.1. Ampla divulgação do sistema............................................ 181

5.4.2.2. Publicação de relatório anual ............................................. 183

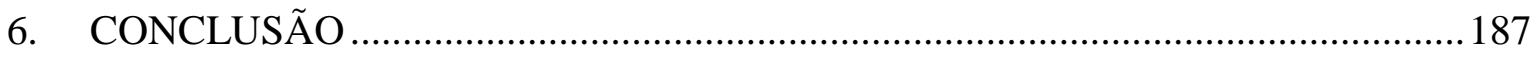

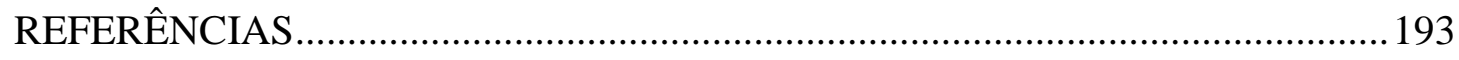

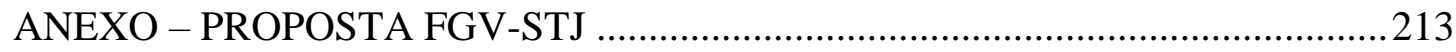





\section{INTRODUÇÃO: NOVOS RUMOS DA RELAÇÃO ENTRE FORNECEDORES E CONSUMIDORES}

A atividade exercida por um fornecedor geralmente não é destinada a um consumidor específico. Pela lógica do lucro e do crescimento empresarial, fornecedores costumam lidar com uma coletividade de consumidores, sempre que os produtos e serviços colocados no mercado possam ser comercializados em grande escala. É esse o caso de empresas destinadas a ramos como telefonia, transporte, seguros e, também, ao ramo das atividades bancárias.

Nesse âmbito, é comum que se verifique certa massificação no tratamento dispensado pelos fornecedores aos consumidores. São informações genéricas, má prestação de serviço, produtos defeituosos e, enfim, tudo o que se pode esperar de um fornecimento em massa, com as falhas e os acertos naturais da atividade empresarial.

Em outras palavras, o fornecimento de produtos e serviços em grande escala dá margem ao surgimento de um maior número de conflitos entre consumidores e fornecedores, em função da multiplicação e massificação das relações jurídicas existentes. Trata-se de conclusão bastante simples. ${ }^{1}$

Não tão simples, porém, é o desempenho da tarefa de resolução desses conflitos. Em uma análise puramente processual, pode-se pensar no ajuizamento de ações judiciais, com pacificação da controvérsia diretamente pelo Estado, na forma do Poder Judiciário.

Por outro lado, em uma análise mais ampla, outros meios podem significar a solução do conflito, e de forma ainda mais adequada do que ordinariamente aquela aplicada pelo Poder Judiciário.

Não há dúvidas de que conflitos entre fornecedores e consumidores devem em regra ser evitados, principalmente porque a relação de consumo não costuma ser pontual. $O$ esperado é que o consumidor volte com frequência a um mesmo fornecedor. Via de regra,

\footnotetext{
"São inúmeros consumidores adquirindo produtos iguais, produzidos em série. Isto faz com que existam diversas relações jurídicas com o mesmo objeto, por exemplo, a compra e venda de determinado eletrodoméstico. Já quanto ao elemento subjetivo, em um lado, estes diversos vínculos convergem no fornecedor do bem, que se torna um polo irradiador de relações jurídicas homogêneas, no outro lado, há uma grande pulverização de sujeitos, os consumidores." OSTIA, Paulo Henrique Raiol. Desenho de Sistema de Resolução de Conflito: Sistemas Indenizatórios em Interesses Individuas Homogêneos. Dissertação de mestrado, Faculdade de Direito da Universidade de São Paulo, 2014.
} 
produtos ou serviços apenas podem ser fornecidos em grande escala se o fornecedor for hábil o suficiente para fidelizar clientes.

Com base nesse mesmo raciocínio, novos jogadores têm apostado crescimento no mercado por meio da criação de uma política de tratamento personalizado ao consumidor, na tentativa de se evitar os efeitos negativos da massificação das relações.

Empresas como Uber, Netflix e Nubank têm utilizado a tecnologia contra a burocracia, apostando em medidas eficientes com o objetivo de alcançar maior satisfação e fidelização do público consumidor.

Sobre o Nubank, fintech ${ }^{2}$ de cartões de crédito que surgiu em 2013 como alternativa a grandes bancos do país, as vantagens destinadas ao consumidor não significaram apenas menores tarifas ou facilidade na obtenção de crédito. De acordo com Victor Oliveira, sócio da empresa:

Também deveríamos fazer nossos clientes se sentirem abraçados e queridos, por meio de um atendimento informal e de qualidade. (...). Eles [funcionários do Nubank] são qualificados para resolver problemas. Além disso, $o$ atendimento vira uma porta de entrada para que a equipe trabalhe em outros setores do Nubank. É mais caro, mas vale a pena. ${ }^{3}$

Essa nova realidade tem sido atentamente examinada pelos grandes bancos. $\mathrm{Na}$ mais recente edição do $26^{\circ}$ Congresso e Exposição de Tecnologia da Informação das Instituições Financeiras, organizado pela Febraban em junho de 2016, especialistas examinaram justamente o fenômeno de fintechs, que têm prometido revolucionar o relacionamento entre bancos e consumidores. ${ }^{4}$

2 O termo "fintech" advém dos vocábulos ingleses finance and technology. Sua origem é atribuída a programa criado pela empresa Accenture, em parceria com a prefeitura de Nova Iorque, para aceleração de novas empresas que conjugassem tecnologia com a área financeira. Após o programa, "fintech" passou a ser usado para a qualificação de empresas que "criam inovações na área de serviços financeiros, com processos baseados em tecnologia.” FINNOVATION. O que é Fintech? Disponível em: <http://finnovation.com.br/oque-e-fintech/>. Acesso em: 23 dez. 2016.

3 LIRA, Adriano. 4 Fatores que Levaram o Nubank ao Sucesso. Pequenas Empresas \& Grandes Negócios, 2016. Disponível em: <http://revistapegn.globo.com/Startups/noticia/2016/05/4-fatores-que-levaram-onubank-ao-sucesso.html>. Acesso em: 17 dez. 2016.

Até junho de 2016, 450.000 (quatrocentos e cinquenta mil) consumidores aguardavam em fila pela possibilidade de contratar os cartões de crédito fornecidos pelo Nubank: TEIXEIRA, Lucas Borges. Como o Nubank virou o queridinho dos jovens brasileiros. 15 jun. 2016. Revista Forbes Brasil. Disponível em: <http://www.forbes.com.br/negocios/2016/06/como-o-nubank-virou-o-queridinho-dos-jovensbrasileiros/>. Acesso em: 30 ago. 2016.

4 CIAB FEBRABAN. Febraban promove encontro com fintechs no Ciab. Disponível em: <http://www.ciab.org.br/pt/noticia/2016/05/febraban-promove-encontro-com-fintechs-no-ciab>. Acesso em: 17 dez. 2016. 
Naquela oportunidade, Roberto Setubal, presidente do Itaú Unibanco S.A., declarou: "Tenho certeza que nós, bancos, temos que correr. (...). A primeira coisa que a gente pensa é o cliente, precisamos construir um negócio que o grande beneficiário seja o cliente. (...). Servir o cliente é uma arte e ela tem que estar sempre sendo aperfeiçoada, desenvolvida." 5

Em paralelo, e sem mais tecer considerações sobre estratégias de negócios de cada banco, entendemos que avanços direcionados ao estreitamento das relações mantidas entre consumidores e bancos são de extrema relevância ao Direito.

Apesar das declarações selecionadas acima, o relatório publicado pelo Conselho Nacional de Justiça em março de 2011 revela uma verdade bastante conhecida: as instituições financeiras chegaram a ocupar 15 dos primeiros 25 lugares na lista dos 100 maiores litigantes do país, ${ }^{6}$ estando no polo passivo da demanda em $55 \%$ dos casos nacionalmente considerados. ${ }^{7}$

Se os bancos realmente pretendem investir em canais mais eficazes de atendimento aos consumidores, tratar-se-á de evidente filtro de novas demandas judiciais. $\mathrm{O}$ melhor tratamento aos conflitos é, aliás, tema muito estudado na atualidade, sob um enfoque especial de acesso à justiça.

Nesse contexto, o estudo abaixo pretende dedicar-se ao exame jurídico da evolução do conceito de acesso à justiça, para alcançar o desenvolvimento de um novo papel das grandes empresas, destinado ao tratamento adequado de conflitos repetitivos ${ }^{8}$ oriundos de suas práticas diárias perante consumidores.

Para melhor ilustração, escolheu-se o caso da relação mantida entre bancos e consumidores, considerando a expressividade que seus conflitos representam ao Poder

5 CALDAS, Edson. "Tenho certeza que nós, bancos, temos que correr", diz Setubal sobre avanço das fintechs: Presidente do Itaú fala sobre o que o banco tem feito para ser mais digital. Mas nega que seja uma estratégia de sobrevivência: “é estratégia de crescimento'.” Época Negócios, 21 jun. 2016. Disponível em: $<$ http://epocanegocios.globo.com/Tecnologia/noticia/2016/06/tenho-certeza-que-nos-bancos-temos-quecorrer-diz-setubal-sobre-avanco-das-fintechs.html.> Acesso em: 17 dez. 2016.

6 BRASIL. Conselho Nacional de Justiça. 100 maiores litigantes: "Tabela 1 - Listagem dos 100 maiores litigantes contendo o percentual de processos em relação aos 100 maiores litigantes da Justiça” mar. 2011. Disponível em: <http://www.cnj.jus.br/images/pesquisasjudiciarias/pesquisa_100_maiores_litigantes.pdf>. Acesso em: 16 jun. 2016.

7 Ibidem.

8 O uso do termo "repetitivos" neste estudo é utilizado de forma ampla, para fazer referência genérica a conflitos que, ainda que não idênticos, envolvem sempre práticas bancárias tidas como abusivas por um ou vários consumidores prejudicados. 
Judiciário e, em especial, um certo reconhecimento pelos próprios bancos sobre uma premente necessidade de mudanças.

Não apenas os consumidores devem procurar a solução amigável dos conflitos, mas sobretudo os bancos devem abrir portas para que essa busca alcance um resultado realmente efetivo. ${ }^{9}$

Para tanto, e de modo a trazer mais praticidade a todo o estudo, serão apresentadas ao final proposições para a implementação de um método de solução extrajudicial de conflitos entre consumidores e bancos, a partir da aplicação da técnica do Desenho de Solução de Disputas (DSD).

9 É o que se busca para adotar, em suma, uma organização social saudável, a partir da eliminação de barreiras que possam significar fatores impeditivos à prevenção de disputas. Sobre isso, ver: FELSTINER, William L.F., ABEL, Richard L., e SARAT, Austin. The Emergence and Transformation of Disputes: Naming, Blaming, Claiming. Law \& Society Review, Salt Lake City, 15, n. 3-4, p. 654, 1980. 


\section{CONCLUSÃO}

A garantia do acesso à ordem jurídica justa é tarefa árdua, que sabidamente não pode ser desempenhada apenas pelo Poder Judiciário. É preciso que outras portas sejam abertas, e que essas portas não dependam unicamente de recursos estatais.

Embora este estudo tenha tratado do congestionamento do Poder Judiciário, não se pretendeu defender que mudanças devem ser implementadas apenas em razão do congestionamento em si. Visto sob outra ótica, o problema está não somente na crise do Poder Judiciário, mas também na necessidade de se pensar na participação da comunidade na administração da Justiça.

Essa participação, por sua vez, pode alcançar efeitos maximizados quando realizada por alguns dos principais entes públicos e privados do país, considerando sua expressiva contribuição aos níveis de litigância enfrentados pelo Poder Judiciário.

Escolheu-se examinar neste estudo o caso dos conflitos existentes entre consumidores e bancos. Referidos conflitos representam uma das maiores causas de congestionamento do Poder Judiciário, por fatores ligados especialmente à multiplicidade de relações existentes na área bancária e a uma noticiada ausência de pré-disposição dos bancos em resolver as controvérsias antes da concretização de um litígio.

Esse cenário de alta litigiosidade é agravado quando se vê que os canais obrigatórios para tratamento de reclamações consumeristas (o SAC e a Ouvidoria) não são utilizados em sua plenitude. Apesar de os bancos insistirem em campanhas publicitárias voltadas à valorização do cliente, são comuns os registros de que as disputas não são facilmente resolvidas de forma amigável. Parcela considerável de consumidores, aliás, sequer conhece a existência e as funções da Ouvidoria regulada pela Resolução CMN $4.433 / 2015$.

Bons avanços, no entanto, têm sido alcançados. Em paralelo à conhecida dificuldade de resolução de disputas de consumo, a comunidade jurídica internacional tem se esforçado para desenhar novas ideias voltadas ao melhor tratamento desses conflitos, a exemplo do Final G20/OCDE High-level Principles on Financial Consumer Protection, em outubro de 2011, e das Diretrizes da Organização das Nações Unidas para Defesa do Consumidor, atualizadas em dezembro de 2015. 
Em termos estritamente brasileiros, outros programas vêm sendo desenhados para essa mesma finalidade, seja por iniciativas públicas ou privadas. É o caso, por exemplo, dos estudados Pacto de Mediação e Programa Empresa da Justiça. Por meio do Pacto de Mediação, como visto, grandes bancos do país se comprometeram a privilegiar o uso de métodos consensuais de resolução de conflitos de consumo. Já o Programa Empresa da Justiça fez com que grandes bancos também se comprometessem também a reduzir em 3\% o número de ações judiciais perante o Tribunal de Justiça do Estado de São Paulo dentro do período de um ano.

Em nosso entender, uma necessidade de desjudicialização pressupõe não propriamente a inexistência de conflitos. Conflitos são intrínsecos a qualquer relação e plenamente admitidos pelo Direito. Cada vez mais, o que se quer buscar na verdade é que esses conflitos recebam tratamento adequado.

Não basta que o consumidor tenha a liberdade de dar início a uma ação judicial. Não basta que o consumidor possa se utilizar de canal disponibilizado pelo banco para fazer uma reclamação. É preciso que o conflito receba o correto encaminhamento, a partir de um sistema célere e eficaz que represente o acesso do consumidor à ordem jurídica justa.

Encontram-se nessa seara os estudos sobre Desenho de Sistema de Disputas (DSD), que permitem a criação de sistemas específicos para conjuntos diferentes de conflitos. A depender das qualidades reunidas por cada conjunto de disputas, é possível o desenho de um procedimento próprio, que dispense a utilização da fórmula padrão normalmente encontrada nos processos estatais.

Para o caso específico dos conflitos entre consumidores e bancos, viu-se que o Serviço de Ombudsman é modelo exitoso de DSD, há muito recepcionado no exterior.

Em suma, o Serviço de Ombudsman é método privado de resolução de disputas entre consumidores e bancos, construído e financiado a partir de recursos conjuntos dos bancos de determinado país. A partir desse financiamento, desenha-se procedimento célere e informal, que pode resultar em determinação vinculante ao banco se assim desejado pelo consumidor.

Este estudo expôs que o desenvolvimento de um modelo de método similar ao Serviço de Ombudsman no Brasil é, além de possível, altamente necessário para a inserção de grandes litigantes como agentes corresponsáveis pela administração da justiça. 
Os primeiros passos para a implementação de um Serviço de Ombudsman de Bancos no Brasil se concretizaram em setembro de 2016, com o I Seminário Ombudsman como Forma de Desjudicialização dos Conflitos na Relação de Consumo, realizado no Superior Tribunal de Justiça, em parceria com a FGV Projetos, a Febraban e o IDP.

O Seminário resultou na edição de uma "proposta de minuta de autorregulação" para implementação do Serviço de Ombudsman no país. Dada a sua relevância, o documento passou a ser denominado neste estudo como "Proposta FGV-STJ" e consta ao final como anexo único desta dissertação.

Paralelamente à atividade da Proposta FGV-STJ, este estudo também se dedicou à elaboração de proposições para a implementação de um modelo-teste de Serviço de Ombudsman no país. Para tanto, foi utilizado como base o exame de alguns dos principais sistemas de Ombudsman Bancário do mundo, em especial os desenhados pela Alemanha, pela Austrália, pelo Canadá e pelo Reino Unido. Em suma:

1. Quanto à natureza do procedimento, chegou-se à conclusão de que, ao contrário do apresentado pela Proposta FGV-STJ, o Serviço de Ombudsman não deveria ser qualificado como uma arbitragem. O Serviço de Ombudsman costuma representar procedimento híbrido, livre para mesclar diferentes técnicas necessárias ao mais adequado tratamento das disputas.

2. Dentro do contexto brasileiro, um bom caminho para a implementação inicial do Serviço de Ombudsman seria por meio do Sistema de Autorregulação Bancária (SARB) da Febraban. Além de já contemplar a adesão dos maiores bancos do país, o SARB ainda desfruta do benefício de ser um mecanismo pronto, com sanções já estabelecidas em caso de descumprimento de suas regras.

3. O financiamento do Serviço de Ombudsman deveria ser integralmente feito pelos bancos em conjunto, a partir de duas modalidades: "contribuição anual" e “contribuição por caso". A contribuição anual corresponderia a um valor pago por todos os bancos aderentes ao Serviço e a contribuição por caso seria paga por cada banco a cada nova reclamação apresentada por um de seus clientes.

4. Por se tratar de sistema específico e custoso aos bancos, foi necessário também pensar em diretrizes para racionalização da atividade do Serviço de Ombudsman. Optou-se, assim, por propor a restrição do uso do sistema a pessoas naturais ou microempreendedores 
individuais e por apenas permitir a emissão de determinações pelo Ombudsman sobre valores limitados a 40 salários mínimos.

5. Quanto à matéria em disputa, examinamos que o Serviço deveria poder excluir a apreciação de: (i) pretensões já prescritas; (ii) reclamações sobre matéria objeto de ação judicial pendente do mesmo consumidor; e (iii) hipóteses excepcionais em que o Serviço de Ombudsman entendesse que a reclamação deveria receber tratamento mais adequado perante o Poder Judiciário.

6. A nomeação do Ombudsman foi idealizada neste estudo de forma a conjugar interesses do setor bancário com os da área da proteção do consumidor. Restou estruturado nosso entendimento no sentido de que o profissional deveria ser nomeado pelo Conselho de Autorregulação Bancária e aprovado pela Secretaria Nacional do Consumidor, para um mandato não inferior a três anos.

7. Proposições para o procedimento também foram examinadas. Em resumo, seria importante que o procedimento do Serviço de Ombudsman garantisse a igualdade substancial entre as partes e, ainda, seguisse de forma célere, informal e privada, ficando dispensada a atuação obrigatória de advogados.

8. Para garantia da igualdade substancial, uma das atividades principais do Serviço de Ombudsman seria o exercício de um papel investigativo a respeito dos fatos relatados de parte a parte (sistema inquisitorial ou "não adversarial"). Seria importante que a definição dos termos de uma recomendação ou determinação não dependesse da capacidade que cada parte possuiria de expor o seu caso. Como sistema ligado aos bancos, o Serviço de Ombudsman deveria possuir ferramentas para buscar diretamente a comprovação dos fatos que entendesse pertinente para o deslinde da controvérsia, ao invés de simplesmente aguardar que as partes expusessem os documentos que bem entendessem.

9. A todo momento, deveriam estar abertas portas para uma possível solução amigável da controvérsia. Por essa razão, propusemos que, uma vez colhidas as informações relevantes e entendida a real situação da controvérsia, o Serviço de Ombudsman poderia sugerir às partes os termos de um possível acordo, em caráter de recomendação.

10. Apenas no caso da não celebração de acordo, o Ombudsman estaria autorizado a proferir determinação final sobre a reclamação. Essa determinação final poderia ser baseada na legislação aplicável, e também naquilo que o Ombudsman considerasse justo e 
razoável, tal como o cumprimento a boas práticas da indústria ou mesmo o conteúdo de determinações anteriormente emitidas pelo Serviço sobre outras reclamações similares.

11. O Ombudsman também poderia considerar uma determinação a ocorrência de danos morais, desde que na modalidade in re ipsa definida pelo Superior Tribunal de Justiça. Para esse caso, propusemos que os danos morais deveriam ser arbitrados em valores menores do que aqueles ordinariamente aplicados no Poder Judiciário, uma vez que, no caso do Serviço de Ombudsman, o banco teria evidente predisposição ao rápido tratamento do conflito.

12. Enquanto o procedimento deveria sempre seguir de forma privada, e os termos de uma recomendação de acordo estariam protegidos por sigilo, a determinação final do Ombudsman poderia ser publicada. A publicidade da determinação contribuiria não apenas para divulgar o entendimento do Serviço de Ombudsman sobre determinadas práticas bancárias, como também para que os consumidores pudessem ficar alerta sobre quais práticas seriam entendidas como abusivas e sobre quais seriam os bancos mais reclamados perante o sistema.

13. A determinação do Ombudsman deveria ser vinculante ao banco, desde que: (i) houvesse concordância expressa do consumidor; e (ii) o valor nela refletido não superasse o limite de 40 salários mínimos.

14. Caso o consumidor discordasse do entendimento exarado pelo Ombudsman, ele permaneceria livre para ajuizar ação perante o Poder Judiciário, ainda que sobre as mesmas bases da reclamação apresentada ao Serviço de Ombudsman.

15. Caso o Ombudsman emitisse posicionamento sobre valor superior ao limite de 40 salários mínimos, essa quantia excedente representaria mera recomendação. Dessa forma, o banco apenas estaria obrigado a pagar 40 salários mínimos (a depender da concordância do consumidor), e seria recomendado a pagar o valor relativo à quantia excedente.

16. Uma forma de vincular o banco ao cumprimento da determinação do Ombudsman seria, além do estabelecimento de multas e demais sanções, a caracterização da determinação como um título executivo extrajudicial. Para tanto, propõe-se também que, caso o consumidor aceite a determinação do Ombudsman, esse consumidor e o banco reclamado deveriam assinar um instrumento por meio do qual o banco confessaria a existência da obrigação determinada pelo Ombudsman, na presença de duas testemunhas, nos termos do artigo 784, inciso III, do Código de Processo Civil. 
17. Para garantia de boa continuidade do sistema, os bancos e o próprio Serviço de Ombudsman (por meio dos recursos que lhe seriam transferidos pelos bancos) deveriam realizar divulgação exaustiva acerca da existência do sistema, suas funções e seus benefícios aos consumidores.

18. Por fim, caberia ao Serviço de Ombudsman a divulgação de relatório anual, com tripla finalidade: prestação de contas para maior alcance de confiança dos atores envolvidos, aprimoramento das práticas adotadas pelo Serviço de Ombudsman e aprimoramento das práticas bancárias.

Uma vez estabelecida a maior facilidade de acesso às portas do Judiciário, é chegado o momento de racionalizar a atividade do Estado. Não nos parece correto admitir o raciocínio de que tudo deve ser resolvido por um juiz.

Ainda que com todas as dificuldades inerentes a grandes mudanças, defendemos que medidas concretas para o alcance de um amplo acesso à justiça podem e devem ser buscadas. O Poder Judiciário é uma estrutura finita e a pacificação social é responsabilidade de todos. 


\section{REFERÊNCIAS}

ABRAHAM, Ann. The Function and Future of the Legal Services Ombudsman. Revista Inter Alia Michaelmas, nº 28/2014, Países Baixos, 2014, p. 28/33.

ALEMANHA. Bankenverband. Rules of procedure for the settlement of customer complaints in the German private commercial banking sector. Disponível em: $<$ https://bankenverband.de/media/publikationen/Verfahrensordnung_Ombudsmann_June2 015_2c_engl.pdf >. Acesso em: 10 nov. 2016.

. Bankenverband. Ombudsman's Report 2011. Disponível em: $<$ https://bankenverband.de/media/publikationen/summary-of-the_lD91G7C.pdf>. Acesso em: 10 nov. 2016.

ALI, Shahla F. Consumer Financial Dispute Resolution in a Comparative Context Principles, Systems and Practice. Reino Unido: Cambridge University Press. 2013.

. Globalization and Financial Dispute Resolution: Examining Areas of Convergence and Informed Divergence in Financial ADR. Journal of Dispute Resolution, Fall Edition, p. 331$347,2013$.

ALVIM, José Eduardo Carreira. Justiça: acesso e descesso. Revista da AJUFE - Associação dos Juízes Federais do Brasil, Brasília, v.21, n.73, p. 165- 83, jan./jun, 2003.

ASPERTI, Maria Cecília de Araújo. STF deve rejeitar acordo de bancos sobre planos econômicos. Revista Consultor Jurídico, 19 mar. 2014. Disponível em: <http://www.conjur.com.br/2014-mar-19/maria-cecilia-asperti-stf-rejeitar-acordo-bancosplanos-economicos>. Acesso: em 26 mar. 2016.

. Meios consensuais de resolução de disputas repetitivas: a conciliação, a mediação e os grandes litigantes do Judiciário. 2014. Tese (mestrado). Faculdade de Direito da Universidade de São Paulo - USP, São Paulo.

. Mudanças propostas no novo CPC necessitam de estudos. Revista Consultor Jurídico, 19 maio 2014. Disponível em: <http://www.conjur.com.br/2014-mai-19/mariaasperti-mudancas-propostas-cpc-necessitam-estudos>. Acesso: em 26 mar. 2016. 
AUSTRÁLIA. Financial Ombudsman Service. Terms of Reference. Disponível em: <https://www.fos.org.au/custom/files/docs/fos-terms-of-reference-1-january-2010-asamended-1-january-2015.pdf>. Acesso em: 10 nov. 2016.

Accessing FOS - how can we help? Disponível em: <https://www.fos.org.au/custom/files/docs/consumer-fact-sheet-on-accessibility.pdf >. Acesso: em 11 nov. 2016.

Advantages of membership. Disponível em: <http://fos.org.au/members/benefits-of-membership.jsp>. Acesso em: 29 ago. 2016

AUSTRÁLIA. Supreme Court of Victoria. Court of Appeals. Mickovski v Financial Ombudsman Service Limited \& Anor [2012] VSCA 185. Julgamento em 17 ago. 2012. Disponível em: $\quad$ emttp://www.austlii.edu.au/cgibin/sinodisp/au/cases/vic/VSCA/2012/185.html?stem=0\&synonyms=0\&query=Mickovski http://www.austlii.edu.au/cgibin/sinodisp/au/cases/vic/VSCA/2012/185.html?stem=0\&synonyms=0\&query=Mickovski >. Acesso em: 3 jan; 2017.

Cromwell Property Securities Limited v Financial Ombudsman Service Limited \& Ors [2014] VSCA 179). Julgamento em 28 ago. 2014. Disponível em: < https://jade.io/article/343364>. Acesso em: 3 jan. 2017.

BAICU, Claudia Gabriela. Legal Aspects and Developments for Financial Consumer Protection: Evidence from the Romanian Banking System. Contemporary Readings in Law and Social Justice, v. 6, item 1, p. 483-490, 2014.

BARROSO FILHO, José. Ouvidoria é um valioso instrumento de resolução de conflitos. Revista Consultor Jurídico, 2 mar. 2015. Disponível em: <http://www.conjur.com.br/2015mar-02/barroso-filho-ouvidoria-valiosa-resolucao-conflitos>. Acesso em: 22 ago. 2016.

BEDAQUE, José Roberto dos Santos. Efetividade do processo e técnica processual. 2.ed., São Paulo, Malheiros, 2007.

BENETI, Sidnei. Ombudsman de Bancos e desjudicialização. 23 set. 2013. Disponível em: <http://www.migalhas.com.br/dePeso/16,MI187050,61044-

Ombudsman+de+Bancos+e+desjudicializacao>. Acesso em: 13 jun. 2016. 
BENJAMIN, Antonio Hermann. O Código Brasileiro de Proteção do Consumidor. Revista de Direito do Consumidor, São Paulo/SP/Brasil, n.7, p. 269/292, jul-set/1993.

BONFANTI, Cristiane. DOCA, Geraldo. Governo lança portal para o consumidor. Jornal O Globo. 27 jun. 2014. Disponível em: <http://oglobo.globo.com/economia/defesa-doconsumidor/governo-lanca-portal-para-consumidor-13035358\#ixzz4KGRCy26t>. Acesso em: 12 set. 2016.

BRASIL. Banco Central do Brasil. Ranking de Instituições Financeiras por Índice de Reclamações. Informações Gerais. Tabela "Bancos e financeiras - Reclamações e quantidades de clientes por instituição financeira." Disponível em: <https://www.bcb.gov.br/ranking/index.asp>. Acesso em: 29 ago. 2016.

Ranking de Instituições Financeiras por Índice de Reclamações. Informações Gerais. Tabela "Bancos e financeiras - Tabela de irregularidades." Disponível em: <https://www.bcb.gov.br/ranking/index.asp>. Acesso em: 29 ago. 2016.

. FAQ - Cartão de Crédito. Atualizado em janeiro de 2017. Disponível em: http://www.bcb.gov.br/?CARTAODECREDITOFAQ\#8. Acesso em: 8 jan. 2017.

BRASIL. Câmara dos Deputados. 20 anos do Real: plano controlou inflação, mas falta crescimento. 27 jun. 2014. Disponível em: http://www2.camara.leg.br/camaranoticias/noticias/ECONOMIA/470831-20-ANOS-DOREAL-PLANO-CONTROLOU-INFLACAO,-MAS-FALTA-CRESCIMENTO.html. Acesso em: 22 jun. 2016.

BRASIL. Congresso Nacional. Senado Federal. Comissão de Juristas responsável pela elaboração de Anteprojeto de Código de Processo Civil. Exposição de motivos. Brasília : Senado Federal, Presidência, 2010.

BRASIL. Conselho da Justiça Federal. Enunciados da I Jornada de Prevenção e Solução Extrajudicial de Litígios. Disponível em: <http://www.cjf.jus.br/cjf/corregedoria-da-justicafederal/centro-de-estudos-judiciarios-1/prevencao-e-solucao-extrajudicial-delitigios/enunciados-aprovados/@@download/arquivo>. Acesso em: 26 dez. 2016.

BRASIL. Conselho Monetário Nacional. Resolução $n^{o} 4.433$, de 23 de julho de 2015. Disponível em: 
<http://www.bcb.gov.br/pre/normativos/res/2015/pdf/res_4433_v1_O.pdf>. Acesso em: 30 dez. 2016.

. Resolução $n 3.694$ de 26 de março de 2009. Disponível em: <http://www.bcb.gov.br/pre/normativos/res/2009/pdf/res_3694_v3_L.pdf>. Acesso em: 3 jan. 2017.

BRASIL. Conselho Nacional de Justiça. 100 maiores litigantes. Brasília, mar. de 2011. Disponível em: <http://www.cnj.jus.br/images/pesquisas-judiciarias/pesquisa_ 100_maiores_litigantes.pdf>. Acesso em: 16 nov. 2016.

. CNJ divulga vencedores do Prêmio "Conciliar é Legal” 2016. 20 dez. 2016. Disponível em: <http://www.cnj.jus.br/noticias/cnj/84236-cnj-divulga-vencedores-dopremio-conciliar-e-legal-2016>. Acesso em: 3 jan. 2017.

. Escolhidos os vencedores do Prêmio Conciliar é Legal. 26 abr. 2016. Disponível em: <http://www.cnj.jus.br/noticias/cnj/82140-escolhidos-os-vencedores-do-premioconciliar-e-legal>. Acesso em: 26 dez. 2016.

. Relatório da Justiça em Números 2013, 15 out. 2013. Disponível em: <http://www.cnj.jus.br/images/variados/capitulo3.zip>. Acesso em: 16 jun. 2016.

. Relatório da Justiça em Números 2014 (ano base 2013). Disponível em: <ftp://ftp.cnj.jus.br/Justica_em_Numeros/relatorio_jn2014.pdf>.Acesso em: 16 jan. 2016.

. Relatório da Justiça em Números 2016 (ano base 2015). Disponível em: <http://www.cnj.jus.br/files/conteudo/arquivo/2016/10/ b8f46be3dbbff344931a933579915488.pdf>. Acesso em: 16 nov. 2016.

. Resolução $n^{\circ} 125$, de 29 de novembro de 2010. Dispõe sobre a Política Judiciária Nacional de tratamento adequado dos conflitos de interesses no âmbito do Poder Judiciário e dá outras providências. Disponível em: <http://www.cnj.jus.br//images/atos_normativos/resolucao/resolucao_125_29112010_1103 2016162839.pdf>. Acesso em: 3 jan. 2017.

Portaria $n^{\circ} 16$, de 26 de fevereiro de 2015. Dispõe sobre as diretrizes de gestão da Presidência do Conselho Nacional de Justiça para o biênio 2015-2016. Disponível em: 
<http://www.cnj.jus.br///images/atos_normativos/portaria/portaria_16_26022015_0303201 5133613.pdf>. Acesso em: 3 jan. 2017.

BRASIL. Governo Federal. Portal Cidadania e Justiça. Disponível em: <http://www.brasil.gov.br/cidadania-e-justica/2016/03/plataforma-consumidor-govsoluciona-79-das-queixas-registradas>. Acesso em: 12 set. 2016.

BRASIL. Ministério da Justiça. Portal Consumidor.gov. Disponível em: <https://www.consumidor.gov.br>. Acesso em: 12 set. 2016.

Portal Consumidor.gov. Termo de Adesão e Compromisso da Plataforma Consumidor.gov. Disponível em: <https://www.consumidor.gov.br/pages/principal/termoadesao-compromisso>. Acesso em: 12 set. 2016.

Portaria $n^{o} 1.184$ de $1^{\circ}$ de julho de 2014. Institui o sistema de solução alternativa de conflitos Consumidor.gov.br. Disponível em: <http://www.lex.com.br/legis_25699631_PORTARIA_N_1184_DE_1_DE_JULHO_DE_ 2014.aspx>. Acesso em: 12 set. 2016.

Portaria $n^{\circ} 2.014$ de 13 de outubro de 2008. Estabelece o tempo máximo para o contato direto com o atendente e o horário de funcionamento no Serviço de Atendimento ao Consumidor - $\quad$ SAC. Disponível em: <http://www.procon.pr.gov.br/arquivos/File/portaria_2_014_08_sac.pdf>. Acesso em: 30 dez. 2016.

Portaria Interinstitucional $n^{o} 1.186$ de 2 de julho de 2014. Institui a Estratégia Nacional de Não Judicialização - Enajud, dispõe sobre a sua gestão e dá outras providências. Diário Oficial da União, Brasília, 3 jul. 2014.

BRASIL. Secretaria de Reforma do Judiciário. Estratégia Nacional de Não Judicialização ENAJUD. $1^{o}$ Relatório 2014-2015. Disponível em: <http://www.acrefi.org.br/enajud/primeiro-relatorio-enajud.pdf>. Acesso em: 30 ago. 2016.

BRASIL. Superior Tribunal de Justiça. Agravo Interno no Agravo em Recurso Especial 851.585/SP, Terceira Turma, rel. Min. João Otávio de Noronha, julgamento em 16 jun. 2016. Diário da Justiça eletrônico, 23 jun. 2016 
Agravo Interno no Agravo em Recurso Especial n ${ }^{\circ} 886.022 / \mathrm{PR}, 4^{\mathrm{a}}$ Turma, rel. Min. Marco Buzzi, julgamento em 1 dez. 2016. Diário da Justiça eletrônico, 7 dez. 2016.

Agravo Regimental no Agravo de Instrumento 524.457/RJ, Terceira Turma, rel. Min. Castro Filho, julgamento em 5 abr. 2005. Diário da Justiça eletrônico, 9 mai. 2005.

. Agravo Regimental no Agravo de Instrumento 1.422.960/SC, Quarta Turma, rel. Min. Maria Isabel Galotti, julgamento em 27 mar. 2012. Diário da Justiça eletrônico, de 9 abr. 2012

Agravo Regimental no Agravo em Recurso Especial 287.762/MG, Terceira Turma, rel. Min. Marco Buzzi, julgamento em 21 jun. 2016. Diário da Justiça eletrônico, 27 jun. 2016

Modelo alemão de mediação é tema de palestra promovida pela Enfam.

Disponível

em:

$<$ http://stj.jus.br/portal_stj/publicacao/engine.wsp?tmp.area=398\&tmp.texto=113205>.

Acesso em: 21 jun. 2016.

. Ministros avaliam que ombudsman bancário pode desafogar sistema judicial.

Disponível

em:

<http://www.stj.jus.br/sites/STJ/default/pt_BR/Comunica\%C3\%A7\%C3\%A3o/noticias/arb itragem/Ministros-avaliam-que-ombudsman-banc\%C3\%A1 rio-pode-desafogar-sistemajudicial>. Acesso em: 9 set. 2016.

. Recurso Especial n 1.110.549/RS, $1^{\text {a }}$ Seção, rel. Min. Mauro Campbell Marques, julgamento em 14 ago. 2013. Diário da Justiça eletrônico, 23 ago. 2013.

. Recurso Especial no 1.061.500/RS, Terceira Turma, rel. Min. Sidnei Beneti, julgamento em 4 nov. 2008. Diário da Justiça eletrônico, 20 nov. 2008.

. Recurso Especial n 656.932/SP, Quarta Turma, rel. Min. Antonio Carlos Ferreira, julgamento em 24 abr. 2008, Diário da Justiça eletrônico, 2 jun. 2014.

. Solução extrajudicial de conflitos exige mudança cultural de operadores do direito. 12 set. $2016 . \quad$ Disponível em: http://www.stj.jus.br/sites/STJ/default/pt_BR/Comunica\%C3\%A7\%C3\%A3o/noticias/Not 
\%C3\%ADcias/Solu\%C3\%A7\%C3\%A3o-extrajudicial-de-conflitos-exigemudan\%C3\%A7a-cultural-de-operadores-do-direito >. Acesso em: 3 jan. 2017.

BRASIL. Presidência da República. Decreto n. 6.253 de 31 de julho de 2008. Regulamenta a Lei n 8.078, de 11 de setembro de 1990, para fixar normas gerais sobre o Serviço de Atendimento ao Consumidor - SAC. Disponível em: <http://www.planalto.gov.br/ccivil_03/_ato2007-2010/2008/decreto/d6523.htm>. Acesso em: 30 dez. 2016.

—. Decreto n. 8.948 de 29 de dezembro de 2016. Regulamenta a Lei no 13.152 , de 29 de julho de 2015, que dispõe sobre o valor do salário mínimo e a sua política de valorização de longo prazo. Disponível em: $<$ http://pesquisa.in.gov.br/imprensa/jsp/visualiza/index.jsp?jornal=1\&pagina $=12 \&$ data $=$ 30/12/2016>. Acesso em: 30 dez. 2016.

Lei $n$. 8.078, de 11 de setembro de 1990. Dispõe sobre a proteção do consumidor e dá outras providências. Disponível em: <https://www.planalto.gov.br/ccivil_03/Leis/ L8078.htm>. Acesso em: 30 dez. 2016.

Lei $n^{o} 9.099$ de 26 de setembro de 1995. Lei dos Juizados Especiais Cíveis. Disponível em: <http://www.planalto.gov.br/ccivil_03/leis/L9099.htm>. Acesso em: 30 dez. 2016.

Lei $n^{o} 9.307$ de 23 de setembro de 1996. Lei de Arbitragem. Disponível em: <http://www.planalto.gov.br/ccivil_03/leis/L9307.htm>. Acesso em: 30 dez. 2016.

Lei n. 13.105, de 16 de março de 2015. Código de Processo Civil. Disponível em: <https://www.planalto.gov.br/ccivil_03/_ato2015-2018/2015/lei/113105.htm>. Acesso em: 30 dez. 2016.

. Lei $n^{o} 13.140$ de 26 de junho de 2015. Lei de Mediação. Disponível em: <http://www.planalto.gov.br/ccivil_03/_ato2015-2018/2015/Lei/L13140.htm>. Acesso em: 30 dez. 2016.

BRASIL. Tribunal de Justiça do Estado de São Paulo. Comunicação Social. G100 Participa do Projeto "Empresa Amiga da Justiça", 16 jun. 2015. Disponível em: 
<http://www.tjsp.jus.br/Institucional/CanaisComunicacao/Noticias/Noticia.aspx? $\mathrm{Id}=26871$ >. Acesso em: 21 jun. 2016.

. Portaria $n^{o} 9.126$ de 25 de fevereiro de 2015. Disponível em: <http://www2.oabsp.org.br/asp/clipping_jur/ClippingJurDetalhe.asp?id_noticias=23347>. Acesso em: 18 jun. 2016 . Processo no 3000114-11.2013.8.26.0428, Foro Distrital de Paulínia, Comarca de Campinas, Diário da Justiça Eletrônico, 16 abr. 2014.

BROOKER, Penny. The "Juridification" of Alternative Dispute Resolution. AngloAmerican Law Review, 28, item 1, p. 1-36, 1999.

BULOS, Jaime Leandro; GERAIGE NETO, Zaiden. Breves considerações sobre a possibilidade de condenação por dano moral coletivo às instituições bancárias, quando prejudicado o cliente-consumidor. Revista de Direito Bancário e do Mercado de Capitais, São Paulo, v. 15, n.57, p. 13-27, jul./set. 2012.

CALDAS, Edson. "Tenho certeza que nós, bancos, temos que correr", diz Setubal sobre avanço das fintechs: Presidente do Itaú fala sobre o que o banco tem feito para ser mais digital. Mas nega que seja uma estratégia de sobrevivência: "é estratégia de crescimento". Época Negócios, 21.jun. 2016.2 Disponível em: $<$ http://epocanegocios.globo.com/Tecnologia/ noticia/2016/06/tenho-certeza-que-nosbancos-temos-que-correr-diz-setubal-sobre-avanco-das-fintechs.html>. Acesso em: $17 \mathrm{dez}$. 2016.

CANADÁ. Canadians Bankers Association. Resolving Problems with your Bank. Disponível em: 〈http://www.cba.ca/resolving-problems-with-your-bank>. Acesso em: 10 nov. 2016.

Ombudsman for Banking Services and Investments. Code of Practice Approved by OBSI's Board of Directors December 2015. Disponível em: <https://www.obsi.ca/download/fm/276>. Acesso em: 30 dez. 2016.

. Consolidation of By-law No. 1 and By-law No. 2. Disponível em: <https://www.obsi.ca/download/fm/275>. Acesso em: 10 nov. 2016. 
Terms of Reference. Disponível em:

<https://www.obsi.ca/en/download/fm/318>. Acesso em: 10 nov. 2016.

CANÁRIO, Pedro. Judicialização cria sociedade que não dialoga. Revista Consultor Jurídico, 7 maio 2012. Disponível em: <http://www.conjur.com.br/2012-mai07/judicializacao-conflitos-cria-sociedade-nao-dialoga-nalini>. Acesso em: 25 mar. 2016. - "Judiciário precisa ser realmente o último recurso da cidadania". Revista Consultor Jurídico, 21 jun. 2015. Disponível em: <http://www.conjur.com.br/2015-jun21/entrevista-luis-felipe-salomao-ministro-superior-tribunal-justica>. Acesso em: 22 ago. 2016.

CANI, Shkelqim. Establishing a Bank Ombudsman in Romania - a background study prepared for the Public-Private Special Projects Initiative (Convergence Financial Sector Modernization), dez. 2006. Disponível em: <http://www.spiromania.eu/admin/filemanager/files/program2007/c_background_study.pdf>. Acesso em: 20 abr. 2015.

CARDOSO, Antonio Pessoa. Quebra do monopólio da Justiça favorece o cidadão. Revista Consultor Jurídico, 11 mai. 2007. Disponível em: <http://www.conjur.com.br/2007-mai11/quebra_monopolio_justica_favorece_cidadao>. Acesso em: 25 mar. 2016.

CARDOSO, Cesar. O Ombudsman Bancário: uma solução adequada de conflitos envolvendo bancos e clientes e seu impacto nos litígios judiciais. 2015. Dissertação de mestrado. Escola de Direito de São Paulo da Fundação Getúlio Vargas, São Paulo.

CARMONA, Carlos Alberto. Arbitragem e processo: um comentário à lei $\mathrm{n}^{\circ}$ 9.307/96. $3^{\mathrm{a}}$ ed., São Paulo: Atlas, 2009.

CAPPELLETTI, Mauro. Os métodos alternativos de solução de conflitos no quadro do movimento universal de acesso à Justiça. Revista de Processo, São Paulo, v.19, n. 74, abr./jun. 1994.

- Alternative Dispute Resolution Processes within the Framework of the World-Wide Access-to-Justice Movement. Modern Law Review, v. 56, p. 282-296, 1993. 
; GARTH, Bryant. Acesso à justiça. Traduzido por Ellen Gracie Northfleet. Porto Alegre: Fabris, 1988.

CAVALIERI FILHO, Sérgio. Programa de Responsabilidade Civil. São Paulo: Atlas, 2007.

CERQUEIRA, Társis Silva de. Acesso à justiça. Novíssima reflexão à luz dos processos repetitivos. Revista Opinião Jurídica, Brasília, v. 8, n. 12, 2010.

CIAB FEBRABAN. Febraban promove encontro com fintechs no Ciab. Disponível em: $<$ http://www.ciab.org.br/pt/noticia/2016/05/febraban-promove-encontro-com-fintechs-nociab>. Acesso em: 17 dez. 2016.

CINTRA, Antônio Carlos de Araújo, GRINOVER, Ada Pellegrini, DINAMARCO, Cândido Rangel. Teoria Geral do Processo. 14. ed. São Paulo: Malheiros, 1998.

CINTRA, Antônio Carlos de Araújo, GRINOVER, Ada Pellegrini, DINAMARCO, Cândido Rangel. Teoria Geral do Processo. 25. ed. São Paulo: Malheiros, 2009.

CONSULTOR JURÍDICO. Advogado deve resolver conflito sem depender do juiz. 10 ago. 2013. Disponível em: <http://www.conjur.com.br/2013-ago-10/advogado-resolver-conflitodepender-juiz-conselheiro>. Acesso em: 26 mar. 2016.

Apesar de baixa confiança, Judiciário recebe uma nova ação a

cada segundo. 18 nov. 2014. Disponível em: <http://www.conjur.com.br/2014-nov18/apesar-baixa-confianca-judiciario-recebe-acao-cada-segundo>. Acesso em: 26 mar. 2016.

. Desjudicialização das relações sociais pode agilizar a Justiça, 5 mai. 2006. Disponível em: <http://www.conjur.com.br/2006-mai05/desjudicializacao_relacoes_sociais_agiliza_justica>. Acesso em: 26 mar. 2016. . Empresas fecharão acordo com governo federal para promover mediação. 16 jun. 2014. Disponível em: <http://www.conjur.com.br/2014-jun-16/empresasfecharao-acordo-governo-federal-promover-mediacao>. Acesso em: 26 mar. 2016.

Empresas transferiram seu call center para o Judiciário. 6 jan.

2013. Disponível em: <http://www.conjur.com.br/2013-jan-06/entrevista-luis-felipesalomao-ministro-superior-tribunal-justica>. Acesso em: 26 mar. 2016. 
São Paulo aprende o caminho das pedras. In: Anuário da Justiça de São Paulo, São Paulo: Conjur Editorial, 2015.

CRAWFORD, Bradley. Financial-Consumer Complaint Agencies. Canadian Business Journal, v. 54, n. 1, p. 68-86.

CRUZ E TUCCI, José Rogério. Arts. $1^{\circ}$ a 12. In: CRUZ E TUCCI, José Rogério; APRIGLIANO, Ricardo de Carvalho; FERREIRA FILHO, Manoel Caetano; DOTTI, Rogéria; e MARTINS, Sandro Gilbert (Org). Código de Processo Civil Anotado. São Paulo: AASP, p. 41. Disponível em: <http://www.aasp.org.br/novo_cpc/ncpc_anotado.pdf>. Acesso em: 25 nov. 2016).

CUNHA, Luciana Gross; BUENO, Rodrigo de Losso Silveira; OLIVEIRA, Fabiana Luci de; SAMPAIO, Joelson de Oliveira; RAMOS, Luciana de Oliveira; MACEDO, Gabriel Hideo Sakai de. Relatório ICJBrasil - $2^{o}$ semestre / 2013. DIREITO GV. Disponível em: <http://hdl.handle.net/10438/11575>. Acesso em: 16 jan. 2016.

CUNHA, Luciana Gross; BUENO, Rodrigo de Losso Silveira; OLIVEIRA, Fabiana Luci de; SAMPAIO, Joelson de Oliveira; RAMOS, Luciana de Oliveira; MACEDO, Gabriel Hideo Sakai de. Relatório ICJBrasil - $2^{o}$ trimestre / 2013 ao $1^{a}$ trimestre / 2014. DIREITO GV. Disponível em: <http://hdl.handle.net/10438/12024>. Acesso em: 16 abr. 2016.

CUNHA, Luciana Gross; BUENO, Rodrigo de Losso Silveira; OLIVEIRA, Fabiana Luci de; SAMPAIO, Joelson de Oliveira; RAMOS, Luciana de Oliveira; MACEDO, Gabriel Hideo Sakai de. Relatório ICJBrasil - $1^{o}$ semestre / 2014. DIREITO GV. Disponível em: <http://hdl.handle.net/10438/12024>. Acesso em: 15 jan. 2016.

CUNHA, Luciana Gross; BUENO, Rodrigo de Losso Silveira; OLIVEIRA, Fabiana Luci de; SAMPAIO, Joelson de Oliveira; RAMOS, Luciana de Oliveira; MACEDO, Gabriel Hideo Sakai de. Relatório ICJBrasil - $2^{o}$ e $3^{\circ}$ trimestres / 2014. DIREITO GV. Disponível em: <http://hdl.handle.net/10438/13599>. Acesso em: 16 jun. 2016.

CUNHA, Luciana Gross; BUENO, Rodrigo de Losso da Silveira; OLIVEIRA, Fabiana Luci de; SAMPAIO, Joelson Oliveira; RAMOS, Luciana de Oliveira; PIERI, Renan Gomes de; CAVALIERI, Cristiana de Jesus Costa. Relatório ICJBrasil - $1^{o}$ semestre 2016. DIREITO GV. Disponível em: <http://hdl.handle.net/10438/17204>. Acesso em: 26 dez. 2016. 
CRISTO, Alessandro. SCOCUGLIA, Livia. Sociedade não pode ser tão dependente do Estado para resolver conflitos. Entrevista com o Professor Kazuo Watanabe. Revista Consultor Jurídico, 9 nov. 2014. Disponível em: <http://www.conjur.com.br/2014-nov09/entrevista-kazuo-watanabe-advogado-desembargador-aposentado-tj-sp>. Acesso em: 30 mar. 2016.

DINAMARCO, Cândido Rangel. Instituições de Direito Processual Civil. São Paulo: Malheiros, 2005. v.1. . Vocabulário de Processo Civil. $2^{\mathrm{a}}$ edição. São Paulo: Malheiros, 2014. Nova era do processo civil. 4. ed. rev. atual. aum. São Paulo: Malheiros, 2013.

FALECK, Diego. Introdução ao design de sistemas de disputas: Câmara de Indenização 3054. Revista Brasileira de Arbitragem, a. 5, n. 23, p.7-32, jul./set. 2009.

FEBRABAN. Código de Autorregulação Bancária. Disponível em: <http://www.febraban.org.br/7Rof7SWg6qmyvwJcFwF7I0aSDf9jyV/sitefebraban/Codigo \%20de\%20Auto-Regulacao\%20Bancaria\%20VF\%20(clean).pdf>. Acesso em: 12 set. 2016.

FEBRABAN. Estatuto Social FB-1133/2007, Federação Brasileira de Bancos, aprovado em 3 jun. 2004 e alterado em 20 jun. 2007. Disponível em: <http://www.febraban.org.br/arquivo/Quemsomos/ESTATUTO.pdf>. Acesso em: 15 set. 2016.

FEBRABAN. Exposição de Motivos do Código de Autorregulação Bancária. Federação Brasileira de Bancos. Disponível em: <http://www.autorregulacaobancaria.org.br/pdf/C\%C3\%B3digo\%20de\%20 Autorregula\%C3\%A7\%C3\%A3o\%20Banc\%C3\%A1ria.pdf>. Acesso em: 12 set. 2016.

FINKLE, Peter; COHEN, David. Consumer Redress through Alternative Dispute resolution and Small Claims Court: Theory and Practice. Windsor Yearbook on Access to Justice, v. 13, p. 81-116, 1993.

FINNOVATION. O que é Fintech? Disponível em: <http://finnovation.com.br/o-que-efintech>. Acesso em: 23 dez. 2016. 
FISS, Owen. Um novo processo civil. São Paulo: Revista dos Tribunais, 2004.

FUNDAÇÃO DE PROTEÇÃO E DEFESA DO CONSUMIDOR. Perfil e Principais Problemas do Usuário Reclamante de Cartão de Crédito. Maio de 2004. Disponível em: <http://www.procon.sp.gov.br/pdf/comport_cartao_credito_2004.pdf〉. Acesso em: 16 jan. 2016.

Ranking das mais reclamadas. São Paulo: Fundação de Proteção e Defesa do Consumidor de São Paulo. Disponível em: 〈http://www.procon.sp.gov.br/pdf/ranking_2015.pdf〉. Acesso em: 30 dez. 2016.

FORGIONI, Paula A. Teoria geral dos contratos empresariais. 2. ed., São Paulo: Revista dos Tribunais, 2010.

GALANTER, Marc. Why the Haves Come Out Ahead: Speculations on the Limits of Legal Change. Law and Society Review, n. 9, 1997.

. A settlement judge not a trial judge: Judicial meditation in the United States. Journal of Law and Society, v. 12, n. 1, p. 1-18, 1985.

. Reading the Landscape of Disputes: What We Know and Don't Know (and Think We Know) About Our Allegedly Contentious and Litigious Society. UCLA Law Review, v. 31, n. 4, p. 4-71, 1983.

. Access to Justice in a World of Expanding Social Capability. Fordham Urban Law Journal, v. 37, p. 115-128, 2010.

GEHLING, Ricardo. Tribunais estão abarrotados de processos irrelevantes. Revista Consultor Jurídico. 12. maio 2005. Disponível em: <http://www.conjur.com.br/2005-mai12/tribunais_abarrotados_processos_irrelevantes>. Acesso em: 26 mar. 2016.

GILSON, Ronald J. MNOOKIN, Robert H. Disputing through agents: cooperation between lawyers in litigation. Columbia Law Review, $\mathrm{n}^{\circ}$ 94, 509, p. 552-553.

GOSS, Joanne. An Introduction to Alternative Dispute Resolution. Alberta Law Review, v. 34, n. 1, p. 1-33, 1995. 
GREEN, Eric D. Corporate Alternative Dispute Resolution. Ohio State Journal On Dispute Resolution, v. 1, n. 2, p. 203-298, 1986.

GRINOVER, Ana Pellegrini. Ensaio sobre a processualidade: fundamentos para uma nova teoria geral do processo. Gazeta Jurídica: Brasília, 2016.

HIRSCH, Günter. The Ombudsman in Germany. Índia, Mumbai, Outubro de 2013. Disponível em: <http://www.emergingmarketsdialogue.org/dms/gizemd/events/event2/Session-5-Speaker-1-Prof.Dr.-Hirsch-Ombudsman-in-

Germany/Session\%205\%20Speaker\%201\%20Prof.Dr.\%20Hirsch\%20Ombudsman\%20in \%20Germany.pdf>. Acesso em: 30 ago. 2016.

HODGIN, R. W. Ombudsmen and Other Complaints Procedures in the Financial Services Sector in the United Kingdom. Anglo-American Law Review, 21, p. 1-19, 1992.

HURTER, Estelle. Access to Justice: To Dream the Impossible Dream. Comparative and International Law Journal of Southern Africa, v.44, n. 3, p. 408-427, 2011

INSTITUTO BRASILEIRO DE DEFESA DO CONSUMIDOR. Eles não aprendem a lição. Revista do Idec, n. 194, dez. 2014, p. 15-17. Disponível em: <http://www.idec.org.br/emacao/revista/bancos-reprovados/materia/eles-no-aprendem-a-lico>. Acesso em: 21 jun. 2016. . Empréstimo "casado". Revista do Idec, n. 191, set. 2014, p. 14-17. Disponível em: <http://www.idec.org.br/emacao/revista/emprestimo-amarrado/materia/emprestimo-casado>. Acesso em: 21 jun. 2016. . Vai um custo a mais aí? Revista do Idec, n. 189, jul. 2014, p. 14-17. Disponível em: <http://www.idec.org.br/emacao/revista/aco-civil-publica-na-berlinda/materia/vai-um-custo-a-mais-ai> . Acesso em: 21 jun. 2016.

INSTITUTO BRASILEIRO DE GEOGRAFIA E ESTATÍSTICA (IBGE). Projeção da população do Brasil e das Unidades da Federação. Disponível em: <http://www.ibge.gov.br/apps/populacao/projecao/>, atualizada em tempo real. Acesso em: 3 jan. 2017. 
. São Paulo»

Jales » inforgráficos: dados gerais do município. Disponível em <http://cidades.ibge.gov.br/painel/painel.php?codmun=352480>. Acesso em: 3 jan. 2017.

LIRA, Adriano. 4 Fatores que Levaram o Nubank ao Sucesso. Pequenas Empresas \& Grandes Negócios, $2016 . \quad$ Disponível em: <http://revistapegn.globo.com/Startups/noticia/2016/05/4-fatores-que-levaram-o-nubankao-sucesso.html>. Acesso em: 17 dez. 2016.

LUCON, Paulo Henrique dos Santos. Novo CPC permite decisões mais rápidas em casos repetidos. Revista Consultor Jurídico, 17 dez. 2014. Disponível em: <http://www.conjur.com.br/2014-dez-17/paulo-lucon-cpc-permite-decisoes-rapidas-casosrepetidos>. Acesso em: 21 jun. 2015.

LUQUES, Ione. STJ propõe discussão sobre ouvidoria especial nos bancos. Jornal O Globo, 17 jul. 2016. Disponível em: <http://oglobo.globo.com/economia/defesa-do-consumidor/stjpropoe-discussao-sobre-ouvidoria-especial-nos-bancos-19733668>. Acesso em: 22 ago. 2016.

MACNEIL, Ian. Consumer dispute resolution in the UK financial sector: the experience of the Financial Ombudsman Service. Law and Financial Markets Review, v. 1, n. 6, p. 515$524,2007$.

MANCUSO, Rodolfo de Camargo. O direito à tutela jurisdicional: o novo enfoque do art. $5^{\circ}$, XXXV, da Constituição Federal. Revista dos Tribunais, São Paulo, a. 101, v.926, p. 135 176, dez. 2012.

MARINONI, Luiz Guilherme. O custo e o tempo do processo civil brasileiro. Revista Forense, Rio de Janeiro, v. 375, p. 81-102, 2004.

MORAES, Alexandre de. Consumidor e direito à prestação jurisdicional eficiente e célere. Revista do Advogado, São Paulo, a. 26, n.89, p.12-20, dez. 2006.

NALINI, José Renato. LEVY, Wilson. Novos amigos para a Justiça. 22 abr. 2015. Disponível em: <http://www.tjsp.jus.br/Institucional/CanaisComunicacao/Noticias/ Noticia.aspx?Id=26338>. Acesso em: 18 jun. 2016. 
NAVES, Nilson. Acesso à justiça. Revista CEJ - Centro de Estudos Judiciários, Brasília, a. 7, n. 22, jul./set. 2003.

NERY JÚNIOR, Nelson. O juiz natural no direito processual civil comunitário europeu. Revista de Processo, São Paulo, v. 101, jan./mar. 2001.

NUNES, Dierle. Sistema processual exige abordagem panorâmica e macroestrutural. Revista Consultor Jurídico. 24 dez. 2013. Disponível em: <http://www.conjur.com.br/2013-dez24/dierle-nunes-sistema-processual-exige-abordagem-panoramica-macroestrutural> . Acesso em: 26 mar. 2016.

NUNES PINTO, José Emílio A confidencialidade na arbitragem. Revista de Arbitragem e Mediação, São Paulo, a. 2, n. 6, p.25-36, jul./set. 2005.

OLIVEIRA, Fabiana Luci; RAMOS, Fabiana de Oliveira; SILVA, Paulo Eduardo Alves da. Estudo de caso em consumidor. In: CUNHA, Luciana Gross. GABBAY, Daniela Monteiro (coord.). Litigiosidade, Morosidade e Litigância repetitiva: uma análise empírica. São Paulo: Saraiva, 2013. (Série Direito e Desenvolvimento - GV).

OLIVEIRA, Fabiana Luci; WADA, Ricardo Morishita. O Comportamento da Nova Classe Média Brasileira nas Relações de Consumo. In: WADA, Ricardo Morishita; OLIVEIRA, Fabiana Luci de (Orgs.). Direito do Consumidor: os 22 anos de vigência do CDC. 1. ed. Rio de Janeiro: Elsevier, 2012. p. 31-49.

ORGANIZAÇÃO DAS NAÇÕES UNIDAS. Guidelines for consumer protection. Disponível em: <http://unctad.org/en/PublicationsLibrary/ditccplpmisc2016d1_en.pdf〉. Acesso em: 3 jan. 2017.

ORGANIZAÇÃO PARA COOPERAÇÃO E DESENVOLVIMENTO ECONÔMICO. Final High-level Principles on Financial Consumer Protection, 13-14 out. 2011. Disponível em: 〈https://www.oecd.org/daf/fin/financial-markets/48892010.pdf>. Acesso em: 30.ago. 2016.

Os bancos com mais clientes no Brasil em 2013. Exame, 1 set. 2014. Disponível em: $<$ http://exame.abril.com.br/revista-exame/noticias/os-bancos-com-mais-clientes-no-brasilem-2013 >. Acesso em: 12 set. 2016. 
OSTIA, Paulo Henrique Raiol. Desenho de Sistema de Resolução de Conflito: Sistemas Indenizatórios em Interesses Individuas Homogêneos. Dissertação de mestrado. Faculdade de Direito da Universidade de São Paulo, 2014.

PEREIRA, José Luiz Parra. Operadores do Direito devem contribuir com desjudicialização. Revista Consultor Jurídico, 23 mar. 2015. Disponível em: <http://www.conjur.com.br/2015mar-23/jose-pereira-advogados-contribuir-desjudicializacao>. Acesso em: 25 mar. 2016.

PROTESTE - ASSOCIAÇÃO BRASILEIRA DE DEFESA DO CONSUMIDOR. Informação é o ponto fraco. Revista Dinheiro \& Direitos, n. 51, agosto-setembro 2014, p. $22-24$. Disponível em: http://www.proteste.org.br/institucional/ /media/lobbyandpressproteste/images/imprensa/p ress-

release/2014/pesquisa\%20da\%20proteste\%20revela\%20baixa\%20satisfa\%C3\%A7\%C3\% A3o $\% 20 \mathrm{dos} \% 20$ consumidores $\% 20 \mathrm{com} \% 20 \mathrm{bancos} /$ satisfacao $\% 20 \mathrm{bancaria} /$ satisfacaobancaria.pdf>. Acesso em: 21 jun. 2016.

RECLAME AQUI. Disponível em: <http://www.reclameaqui.com.br/>. Acesso em: 12 set. 2016

REICHELT, Luis Alberto. Efetividade do processo, tutela jurisdicional do consumidor e direito ao processo justo. Revista de Direito do Consumidor, São Paulo, a. 23, n.91, jan./fev. 2014.

REINO UNIDO. FCA Handbook on Dispute Resolution. Disponível em: <https://www.handbook.fca.org.uk/handbook/DISP.pdf>. Acesso em: 10 nov. 2016.

REINO UNIDO. Financial Ombudsman Service. Consumer factsheet on what a 'final decision' by an ombudsman means. Disponível em: <http://www.financialombudsman.org.uk/publications/factsheets/final_decision.pdf>. Acesso em: 29 nov. 2016 . Annual Review 2016. Referente ao ano-calendário 2015. Disponível em: <http://www.financial-ombudsman.org.uk/publications/ annual-review-2016/ar16.pdf>. Acesso em: 10 nov. 2016.

. Our consumer leaflet. Disponível em: <http://www.financialombudsman.org.uk/publications/consumer-leaflet.htm>. Acesso em: 11 nov. 2016. 
RHODE, Deborah L. Access to Justice. Fordham Law Review, v. 73, n. 3, p. 841-849, 2004.

ROACH, Kent; SOSSIN, Lorne. Access to Justice and Beyond. University of Toronto Law Journal, v. 60, p. 373-395, 2010.

ROGERS, Nancy; BORDONE C. Robert; SANDER, Frank E. A.; MCEVEN, Craig A. Designing Systems and Processes for Managing Disputes. Aspen Publishers, Estados Unidos da América: Wolters Kluwer, 2013.

ROSU, Angelica. Dispute Settlement through Banking Mediation. Acta Universitatis Danubius Journal, v. 8, n. 3, p. 48-55, 2010.

ROVER, Tadeu. Reduzir demanda do Judiciário não vai prejudicar advocacia, afirma OAB. Revista Consultor Jurídico, 28 jul. 2014. Disponível em: <http://www.conjur.com.br/2014jul-28/reduzir-demanda-judiciario-nao-prejudica-advocacia-oab>. Acesso em: 25 mar. 2016.

SADEK, Maria Tereza. Acesso à Justiça: visão da sociedade. Justitia, v. 65, n. 198, p. 271 279, jun. 2008. Judiciário: mudanças e reformas. Estudos Avançados, v. 18, n. 51, p. 79-101, 2004. Justiça em números: novos ângulos. Brasília: Associação dos Magistrados Brasileiros - $2009 . \quad$ AMB, Disponível em: <http://www.amb.com.br/docs/noticias/2009/AMB_Sadek_Justica_em_numeros_novos_a ngulos.pdf>. Acesso em: 22 jun. 2016.

SALLES, Carlos Alberto de. Arbitragem em contratos administrativos. $1^{\text {a }}$ Edição. Rio de Janeiro: Forense, 2011.

- Mecanismos alternativos de solução de controvérsias e acesso à justiça: a inafastabilidade da tutela jurisdicional recolocada. In: FUX, Luiz; NERY JR, Nelson, WAMBIER, Teresa (Org.). Processo e Constituição: Estudos em homenagem ao professor José Carlos Barbosa Moreira. São Paulo: RT, 2006.

. O direito do consumidor e suas influências sobre os mecanismos de regulação do mercado. Revista de Direito do Consumidor, São Paulo, n.17, p. 85-96, jan./mar. 1996. 
SINGER, Linda R. Nonjudicial Dispute Resolution Mechanisms: The Effects On Justice for The Poor. Clearinghouse Review, p. 569-583, 1979.

SOARES, Flaviana. Novas regras sobre o atendimento telefônico ao consumidor. Revista de Direito do Consumidor, São Paulo, a. 17, n.68, p. 95-96, out./dez. 2008.

SOUZA, Artur César de. Demora em julgamentos torna inócua ferramenta de demandas repetitivas. Revista Consultor Jurídico, 20 fev. 2015. Disponível em: <http://www.conjur.com.br/2015-fev-20/artur-souza-demora-torna-inocua-ferramentademandas-repetitivas>. Acesso em: 26 mar. 2016.

STERNLIGHT, Jean R. Dispute Resolution and the Quest for Justice. Dispute Resolution Magazine, v. 1, n. 1, p. 14-19, 2007.

TAYLOR, Thomas F. The Impact of Consumer Protection on Banking Legislation in the European Community and the Effect of the Recent Consumer Protection Proposals. Fordam International Law Jornal, v. 28, n. 1216, p. 1216-1256, 2005.

TEIXEIRA, Lucas Borges. Como o Nubank virou o queridinho dos jovens brasileiros. 15 jun. 2016. Revista Forbes Brasil. Disponível em: <http://www.forbes.com.br/negocios/2016/06/como-o-nubank-virou-o-queridinho-dosjovens-brasileiros/>. Acesso em: 30 ago. 2016.

TENENBLAT, Fábio. Limitar o acesso ao poder judiciário para ampliar o acesso à justiça. Revista CEJ - Centro de Estudos Judiciários, Brasília, v.15, n.52, jan./mar. 2011.

UNIÃO EUROPEIA. Recomendação $n^{\circ}$ 257, de 30 de março de 1998. Disponível em: <http://eur-lex.europa.eu/legal-content/PT/TXT/?uri=URISERV\%3A132031>. Acesso em: 10 nov. 2016.

UNIÃO EUROPEIA, Tratado da União Europeia. 7 de fevereiro de 1992, Jornal Oficial das Comunidades Europeias, $\mathrm{n}^{\mathrm{o}}$ 191. Disponível em: <http://eur-lex.europa.eu/legalcontent/PT/TXT/PDF/?uri=CELEX:11992M/TXT\&qid=1435261624270\&from=EN>. Acesso em: 25 jun. 2016. 
URY, William L.; BRETT, Jeanne M.; GOLDBERG, Stephen B. Getting Disputes Resolved: designing systems to cut the costs of conflict. $1^{\mathrm{a}}$ Edição. São Francisco: JosseyBass Publishers, 1988.

WATANABE, Kazuo. Acesso à Justiça e Sociedade Moderna. GRINOVER, Ada Pellegrini; DINAMARCO, Cândido Rangel; WATANABE, Kazuo, (coords.). Participação $e$ Processo. São Paulo: Revista dos Tribunais, 1988.

Tutela antecipatória e tutela específica das obrigações de fazer e não fazer - arts. 273 e 461, CPC. Revista de Direito do Consumidor, São Paulo/SP/Brasil, n.19, jul-set/1996, p. 77-101.

YEUNG, L.; AZEVEDO, P. F. Beyond conventional wisdom and anedoctal evidence: measuring efficiency of Brazilian courts. Annual Conference of the International Society for New Institutional Economics (13:Berkeley:2009). Disponível em: <http://extranet.isnie.org/uploads/isnie2009/yeung_azevedo.pdf>. Acesso em: 20 jan. 2016. 


\section{ANEXO - Proposta FGV-STJ}

Um Modelo de Ombudsman Bancário para o Brasil.

I Seminário Ombudsman como Forma de Desjudicialização dos Conflitos na Relação de Consumo. 



\title{
PAINEL I: A FIGURA DO OMBUDSMAN NOS SISTEMAS GERMÂNICO E BRITÂNICO DE RESOLUÇÃO DE CONFLITOS FINANCEIROS
}

\author{
Painelistas: \\ Peter Sester | Professor da Universidade de Saint Gallen. \\ David Hazell | Diretor-Executivo de Ética e Compliance do Santander no Reino Unido.
}

Moderador:

Jose Roberto Neves Amorim | Desembargador do Tribunal de Justiça do Estado de São Paulo.

Objetivos: O objetivo principal deste painel foi apresentar a figura do ombudsman e a sua atuação nos sistemas germânico, suíço e britânico, que são considerados de referência na utilização do instituto no mundo.

Breve síntese do painel:

O professor Peter Sester iniciou o painel apresentando os sistemas Germânico e Suíço. Dentro destes dois sistemas, destacou que o ombudsman é de fato uma ferramenta para evitar processos longos e dispendiosos e ressaltou três pontos que devem ser pensados no caso da implementação do ombudsman no Brasil, quais sejam:

- A gratuidade na utilização do ombudsman pelos clientes, que geralmente só são considerados para o pagamento de custas do procedimento quando se tratar de um caso mais complexo;

- Se a utilização do ombudsman como uma alternativa ao processo judicial suspenderá ou não os prazos de prescrição e decadência para postulação em juízo; e, por fim,

- Se a proposta de resolução do ombudsman terá ou não o poder de vincular, isto é, obrigar, a instituição financeira, lembrando que as conclusões do Ombudsman nunca vincularão o consumidor.

Em seguida, David Hazell, o segundo painelista, apresentou o sistema de ombudsman britânico, que atua naqueles casos em que a própria instituição, utilizando os seus próprios meios e técnicas para solução de disputas, não for bem-sucedida, ou quando, apesar de a solução ser oferecida pela instituição, o cliente decidir por acionar o ombudsman e a Financial Ombudsman Service (FOS). Hazell também enfatizou que o serviço de ombudsman deve ser sempre gratuito para o consumidor, sendo o custo repassado para as instituições financeiras. Ele concluiu sua apresentação remarcando a importância de se investir na conscientização dos consumidores para a utilização do ombudsman e ressaltando que a credibilidade como algo fundamental para que a indústria financeira confie no instituto e para que 


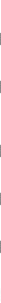

os consumidores possam buscá-lo antes mesmo do processo judicial. Além disso, o painelista indicou ser imprescindível que os consumidores tenham fácil acesso ao ombudsman. Nesse sentindo, deve-se refletir quais seriam as barreiras que podem impedir o acesso ao instituto. Por fim, enalteceu a necessidade de se estar preparado para lidar com os níveis crescentes de reclamações que a implementação do ombudsman pode causar.

A exposição do painel foi finalizada com a intervenção do Desembargador Neves Amorim, que pontuou duas experiências de êxito de desjudicialização. A primeira foi a criação de núcleos de mediação dentro das instituições bancárias, nas quais os facilitadores são os próprios funcionários da instituição, o que contribuiu para a fidelização do cliente. A segunda experiência lembrada foi a instalação de um Centro Judiciário de Solução de Conflitos e Cidadania (CEJUSC), com o apoio da FEBRABAN, dentro do judiciário para receber as conciliações e mediações pré-processuais e processuais, conferindo aos cidadãos maior acesso aos meios extrajudiciais de solução de conflitos. 


\title{
PAINEL II: A IMPORTÂNCIA SOCIOECONÔMICA DA DESJUDICIALIZA- ÇÃO DOS CONFLITOS DE CONSUMO
}

\author{
Painelistas: \\ Luis Felipe Salomão | Ministro do Superior Tribunal de Justiça \\ Kazuo Watanabe | Professor da Universidade de São Paulo
}

Moderador:

João Otávio Noronha | Ministro do Superior Tribunal de Justiça

Objetivos: O objetivo deste painel foi discutir o impacto da judicialização dos conflitos de consumo na ordem socioeconômica e a importância de se combater esta judicialização por meio de meios extrajudiciais de soluções de conflitos, como o ombudsman.

Breve síntese do painel:

O Ministro Luis Felipe Salomão iniciou a exposição do painel explicitando que atualmente os bancos e as instituições financeiras estão em segundo lugar no ranking dos maiores litigantes do Brasil. O Ministro destacou o artigo $4^{\circ}$, inciso V, do Código de Defesa do Consumidor, que trata da obrigatoriedade da implementação de políticas públicas e privadas, por parte dos fornecedores, para a implantação de métodos alternativos de resolução de conflitos. Para ele, esta norma não é meramente programática, havendo a intenção de o legislador impor uma obrigação aos fornecedores. No entanto, por mais que exista esta obrigação, não há meios sancionatórios que possam efetivamente obrigar os fornecedores, sendo somente possível estimulá-los, por intermédio de benefícios fiscais, por eventuais descontos no ajuizamento de suas próprias demandas, entre outras formas de incentivo.

Por fim, o Ministro destacou que uma das saídas para o problema que o Judiciário enfrenta com o alto número de demandas relacionadas a disputas de consumo é a criação de modelos e programas que busquem solucionar estes conflitos extrajudicialmente. Para que isso seja alcançado, é necessária uma mudança na mentalidade e na cultura do litígio no Brasil. O painelista evidenciou ainda alguns passos já dados em direção à modificação dessa cultura, como os enunciados debatidos nas Jornadas de Prevenção e Solução Extrajudicial de Conflitos. Outras soluções apontadas pelo Ministro foram: 


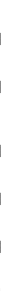

- O uso de plataformas de mediação online; desenhos de novos designs para a solução extrajudicial de conflitos (como o ombudsman);

- A possibilidade de utilização da arbitragem nas relações de consumo, confirmada pelo precedente derivado do Recurso Especial $n^{\circ}$. 1.189.050, cláusulas de mediação nas relações de consumo (amparada pelo art. $2^{\circ}, \S 1^{\circ}$ Lei da Mediação);

- A implementação de uma disciplina obrigatória de mediação nas universidades.

O painel seguinte foi conduzido pelo Professor Kazuo Watanabe, que enfatizou o excessivo volume de conflitos no Judiciário brasileiro e a interpretação equivocada do princípio do acesso à Justiça (Art $5^{a}$, inciso XXXV, da Constituição da República Federativa do Brasil, de 1988). Para ele, este princípio não requer, necessariamente, o ingresso nos órgãos do Poder Judiciário e tampouco a solução dos conflitos por meio do processo judicial.

Watanabe então destacou que a questão fundamental do ombudsman no ordenamento brasileiro é pensar de que forma estruturar-se-á o ombudsman e como criar uma prática que convença os consumidores a acreditar no instituto, pois, pelo princípio do acesso à Justiça, os consumidores não estarão obrigados a buscar o serviço do ombudsman, que seria uma mera faculdade e, portanto, deve-se elaborar uma estratégia para conquistar a confiabilidade do consumidor. Isso porque, segundo Watanabe, a confiança dos consumidores no ombudsman é necessária e fundamental para que este sistema seja bem-sucedido. Por fim, a exposição foi encerrada com a menção de que a importância da proposta de criação do ombudsman consiste em promover uma mudança de mentalidade que reflita na prática das instituições financeiras.

Finalmente, com a intervenção do Ministro João Otávio de Noronha, foi analisada a relevância da compreensão entre o monopólio da jurisdição e o monopólio da Justiça. Segundo o Ministro Noronha, a Constituição confere ao Estado o monopólio da jurisdição, mas não o monopólio da Justiça.

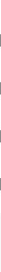


 \\ PAINEL III: ELEMENTOS DE JUDICIALIZAÇÃO DE CONFLITOS DE CONSU- MO NO BRASIL
}

\author{
Painelistas \\ Maria Tereza Sadek | Professora da Universidade de São Paulo. \\ Alexandre de Moraes | Ministro da Justiça. \\ Gilvandro Araújo | Conselheiro do Conselho Administrativo de Defesa Econômica. \\ Luciano Godoy | Advogado.
}

\section{Moderador:}

Ricardo Villas Bôas Cueva | Ministro do Superior Tribunal de Justiça.

Objetivos: O painel teve como objetivo o debate dos principais elementos que levam à judicialização dos conflitos de consumo no Brasil, assim como a abordagem de algumas soluções que podem auxiliar na desjudicialização destes conflitos.

BREVE SÍNTESE DO PAINEL: O painel começou com a exposição da professora Maria Tereza Sadek, que trabalhou a questão do entrave judicial causado pelos 100 maiores litigantes do país, concluindo que o espaço para o cidadão litigar restou diminuto, já que esses maiores litigantes são responsáveis pela concentração de litígios nos tribunais, trazendo morosidade a outros conflitos importantes e concentrando o serviço jurisdicional nas mãos de poucos usuários. Para Maria Tereza, a causa desse entrave é a cultura da judicialização na sociedade brasileira, principalmente com relação a determinados segmentos, como bancos e órgão públicos. Por fim, ela afirmou serem necessários a resolução dessa questão relacionada aos maiores usuários do sistema judicial e o encontro de formas alternativas de solução de conflito, com o consequente alívio ao Judiciário, universalizando o acesso à Justiça e mudando o perfil dos usuários dos tribunais. Além disso, ela frisou a importância específica de diminuir a hiperjudicialização de disputas que envolvem o consumidor.

A segunda exposição do painel foi conduzida pelo conselheiro do Conselho Administrativo de Defesa Econômica (CADE) Gilvandro Araújo, que iniciou sua fala demonstrando como a experiência brasileira de combate aos crimes de ordem econômica, com a evolução no combate aos cartéis por meio de instituições como o CADE, Ministérios Públicos, polícias e demais órgãos de Controle, ou seja, o enforcement público, criou condições para o surgimento das ações de reparação nas relações de consumo. Araújo também demonstrou como a potencialização da judicialização afeta a prestação jurisdicional, pois, para ele, o principal fator disso seria o uso excessivo de pedidos de dano moral, resultado da aplicação das regras do Direito do Consumidor, como o Princípio da Reparação Integral e a responsabilida-

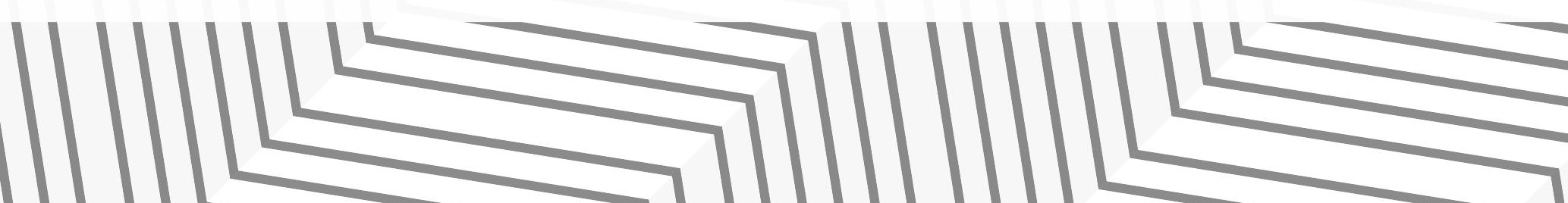




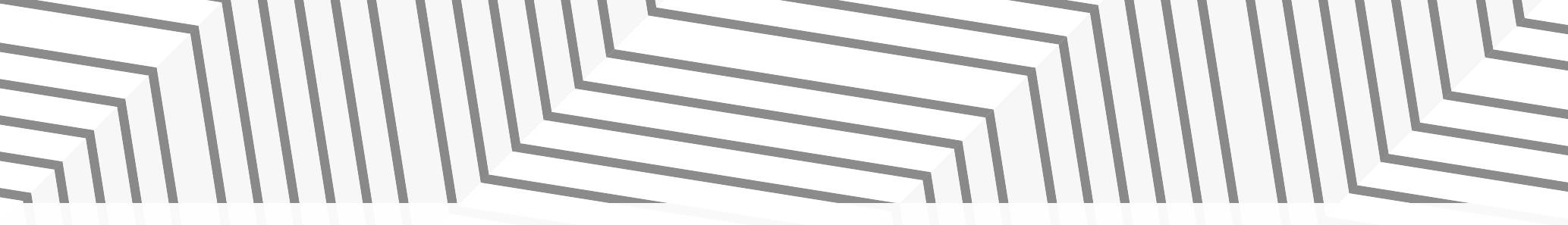

de solidária dos fornecedores em face do consumidor. Ao final de sua explanação, Araújo prescreveu algumas possíveis soluções. Dentre elas, citou a modernização das empresas por meio do instituto do compliance, a necessidade de correlação entre o enforcement público e o privado e a utilização dos mecanismos de mediação e arbitragem para a reparação de danos por infrações concorrenciais.

O professor Luciano Godoi concentrou sua fala nas questões da inexigibilidade do esgotamento das vias administrativas no ajuizamento de reclamações contra o sistema bancário e dos problemas no sistema de honorários de sucumbência. Em seguida, realçou o sistema precedente no Novo Código de Processo Civil e traçou um paralelo entre o sistema de honorários e a judicialização das disputas dos cidadãos. Por fim, foram elencadas algumas possíveis soluções para as questões quanto ao ombudsman bancário, entre elas:

- O reforço do exaurimento das vias administrativas;

- O reforço de canais de reclamação;

- A criação de um canal obrigatório alternativo ao Judiciário antes do ajuizamento da ação;

- A ampliação da participação de advogados na busca de soluções extrajudiciais;

- A revisão do instituto de honorários de sucumbência;

- A valorização dos precedentes.

O último painelista, o Ministro Alexandre de Moraes criticou o atual sistema judicial e afirmou que há mecanismos que facilitam a entrada de processos, mas dificultam sua resolução. Segundo o Ministro, essa estrutura processual alimenta a cultura de litígio entre os que precisam da Justiça e isso atravanca o serviço público que é a prestação jurisdicional. Além disso, Moraes pontuou a problemática da universalização do acesso à Justiça sem uma infraestrutura adequada à efetivação dos direitos dos jurisdicionados e a implementação de Câmaras de Mediação indiscriminadamente sem uma cultura pacífica de litígios. Algumas das soluções para estes problemas propostas por ele foram:

- A utilização do Ministério Público como conciliador nas comarcas do interior, ou uma autoridade presente em quem o povo confie; a criação de confiança nos mecanismos alternativos ao Judiciário para a resolução das disputas. Por derradeiro, indicou que é preciso melhorar o serviço público de Justiça, sem que o usuário necessite tanto do Judiciário.

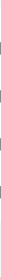


 \\ PAINEL IV: EXPERIÊNCIAS ATUAIS PARA A DESJUDICIALIZAÇÃO DOS CONFLITOS DE CONSUMO: PLATAFORMAS PÚBLICAS E PRIVADAS DE RESOLUÇÃO DE DISPUTAS
}

\author{
Painelistas: \\ Carlos Eduardo Richinitti | Desembargador do Tribunal de Justiça do Rio Grande do Sul. \\ Cesar Cardoso | Procurador do Banco Central. \\ Armando Luiz Rovai | Secretário Nacional do Consumidor.
}

Moderador:

Paulo de Tarso Sanseverino | Ministro do Superior Tribunal de Justiça.

OBJETIVOS: O objetivo deste painel foi trazer alguns exemplos bem-sucedidos de plataformas públicas e privadas que têm sido utilizadas no Brasil como forma de resolução de conflitos de consumo, contribuindo assim para a desjudicialização destes conflitos.

Breve síntese do painel:

O Desembargador Carlos Eduardo Richinitti iniciou os trabalhos do segundo painel do segundo dia do evento criticando as insistentes tentativas de se aprimorar o sistema processual por meio de discussões acadêmicas e legislativas. O magistrado acredita que a revolução no Judiciário dar-se-á pela jurisprudência e não apenas por mudanças na lei. O ponto principal levantado pelo Desembargador foi o problema do dano desejado, que fomenta um verdadeiro mercado do dano moral dentro do Direito do Consumidor. Ele defendeu a ênfase ao instituto do Dano Moral Coletivo, cujo alcance pode ajudar a destravar o Judiciário. Explanou, por fim, que sua concepção de Justiça é a de efetividade na resolução de problemas dos cidadãos. Portanto, o sistema tem de permitir que os juízes se detenham às questões que realmente demandem uma solução estatal e que, nos demais casos, as pessoas resolvam seus problemas entre si de forma extrajudicial.

Na segunda etapa do painel, Cesar Cardoso, Procurador do Banco Central, levantou a questão do ombudsman organizacional X ombudsman setorial, explicando os conceitos e trançando um paralelo entre os dois institutos. Conforme a explicação, o ombudsman organizacional capta os anseios dos clientes e os leva à empresa, visando mais o aspecto global, cujo foco é evitar que tais problemas se renovem no futuro (prevenção). Por sua vez, o ombudsman setorial tem como foco a resolução de conflitos entre clientes e bancos e seus impactos só acontecem paulatinamente, dependendo da dicotomia entre a cultura da litigância versus a cultura da conciliação. Este tipo de ombudsman requer estímulos para que os clientes reconheçam no instituto uma ferramenta de solução de conflitos frente aos bancos.

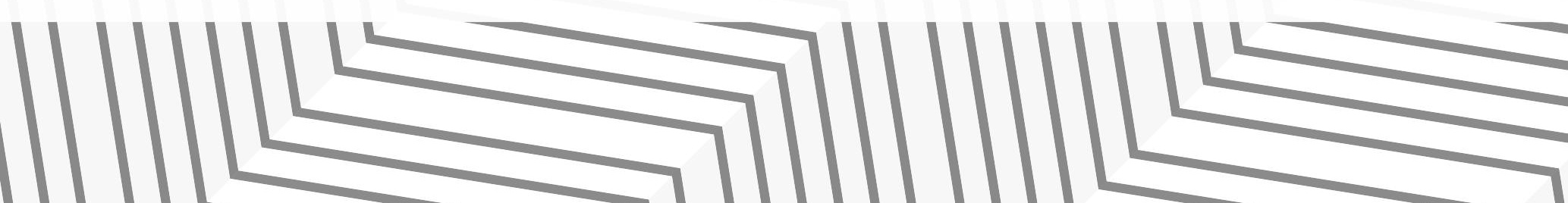




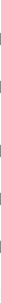

A últimas ponderações do dia foram do Secretário Nacional do Consumidor, Armando Luiz Rovai. Sua abordagem teve como foco a iniciativa do governo federal com a plataforma Consumidor.gov. Segundo ele, essa plataforma foi responsável por $80 \%$ dos acordos firmados sobre o total das demandas que ingressaram no sistema, o que reforça a necessidade da criação de plataformas online que possibilitem a realização de uma mediação digital, de forma a reduzir os custos com a Justiça e a morosidade que o sistema judicial pode acarretar. Rovai lembrou, ainda, do estímulo constante que se deve ter para transformar a cultura de litígio do país, sem perder o empoderamento dos consumidores, algo que foi conquistado com o advento do Código de Defesa do Consumidor. Por fim, propôs algumas soluções para o aprimoramento do sistema de resolução de disputas, quais sejam:

- A unificação dos canais de reclamação dos consumidores;

- A criação de centros universitários com operadores do direito adaptados cultura da solução de conflitos. 
 DAS MESAS DE DEBATES OMBUDSMAN NÓ SETOR BANCÁRIO}

O Sistema de Autorregulação Bancária que institui o Ombudsman no setor bancário e estabelece o procedimento a ser adotado no âmbito das controvérsias decorrentes da contratação de operações e da prestação de serviços em que são partes instituições financeiras.

\section{DO OMBUDSMAN}

Art. $1^{\circ}$ Fica instituído o Ombudsman no Setor Bancário ("Ombudsman").

Art. $2^{\circ} \mathrm{O}$ Ombudsman é um mecanismo, imparcial e independente, de resolução de controvérsias, decorrentes da relação de consumo envolvendo as instituições financeiras signatárias e seus respectivos clientes ("Reclamações").

\section{DA COMPETÊNCIA}

Art. $3^{\circ} \mathrm{O}$ Ombudsman tem como atribuição receber reclamações de clientes das instituições signatárias e solucionar as disputas, por meio de conciliação, de mediação e de determinação nas decisões.

$\S 1^{\circ} \mathrm{O}$ Ombudsman tem competência para as Reclamações que não excedam 40 (quarenta) vezes o salário mínimo, inclusive as envolvendo discordância das condições das operações de crédito, conhecidas como "revisionais de crédito."

§ $2^{\circ}$ A competência do Ombudsman fica restrita à conciliação nas Reclamações relacionadas exclusivamente a pedidos de renegociação de dívidas.

Art. $4^{\circ}$ Os atos procedimentais do Ombudsman deverão ser conduzidos pela mínima formalidade, respeitado contraditório, imparcialidade, legalidade, transparência, celeridade e eficiência, devendo as decisões serem escritas e motivadas de forma objetiva e compreensível para o cliente.

\section{DOS MEMBROS DO OMBUDSMAN}

Art. $5^{\circ} \mathrm{O}$ Ombudsman será composto por 5 (cinco) membros escolhidos dentre as pessoas com reputação ilibada e notável saber jurídico, sem vínculo com o setor bancário ou com entidades de defesa do consumidor há pelo menos 6 (seis) meses, e aprovados pelo Conselho de Autorregulação Bancária, para um exercício de 4 (quatro) anos, podendo ser reconduzidos por iguais e sucessivos períodos.

Art. $6^{\circ}$ Ombudsman possuirá um presidente ("Ombudsman Presidente"), o qual será eleito pelos seus membros para um mandato de 2 (dois) anos, podendo ser reconduzido por iguais e sucessivos períodos.

Art. $7^{\circ}$ Os membros do Ombudsman possuirão uma remuneração mensal de $R \$$ ( mil reais), reajustada ao término de cada ano civil pelo Índice Nacional de Preços ao Consumidor Amplo (IPCA). 


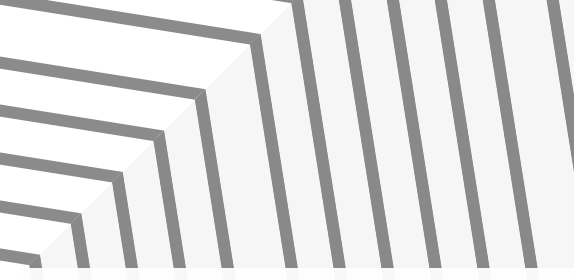

Art. $8^{\circ}$ O Ombudsman não poderá ser destituído de suas funções, durante o mandato, a não ser em caso de falta grave, por decisão do Conselho de Autorregulação, observado o devido procedimento administrativo.

\section{DAS PARTES}

Art. $9^{\circ}$ Poderão propor Reclamações perante o Ombudsman as pessoas físicas ou as pessoas jurídicas consideradas como microempreendedores individuais.

Art. $10^{\circ}$ As partes poderão ser assistidas por advogado.

Art. $11^{\circ}$ Sempre a que a Reclamação for procedente e o cliente estiver assistido por advogado, a instituição financeira deverá arcar com o custo dos honorários advocatícios, no valor constante da Tabela de Honorários da Ordem dos Advogados do Brasil para Conciliação e Mediação Extrajudicial, a serem pagos diretamente ao advogado, exceto se este explicitamente renunciar a remuneração.

\section{DO PROCEDIMENTO DE RESOLUÇÃO DE CONTROVÉRSIAS}

\section{SEÇÃO I DISPOSIÇÕES GERAIS}

Art. $12^{\circ}$ Os atos procedimentais serão exclusivamente por meio eletrônico e estarão disponíveis em site na internet.

\section{SEÇÃO II DO PEDIDO}

Art. $13^{\circ} \mathrm{O}$ procedimento de resolução de controvérsias instaurar-se-á com a apresentação pelo cliente de seu pedido, por escrito, no site eletrônico do Ombudsman.

$\S 1^{\circ}$ Do pedido constarão, de forma simples e em linguagem acessível:

I - o nome, a qualificação e o endereço das partes;

II - os fatos e os fundamentos, de forma sucinta; e

III - o objeto e seu valor.

$\S 2^{\circ} \mathrm{O}$ pedido deverá ser acompanhado de:

I - comprovante de tentativa de solução direta com a instituição financeira por meio do Serviço de Atendimento ao Consumidor (SAC) ou por meio de órgãos de defesa do consumidor (Procon ou portal www.consumidor.gov.br); e

II - procuração, se assistido por advogado.

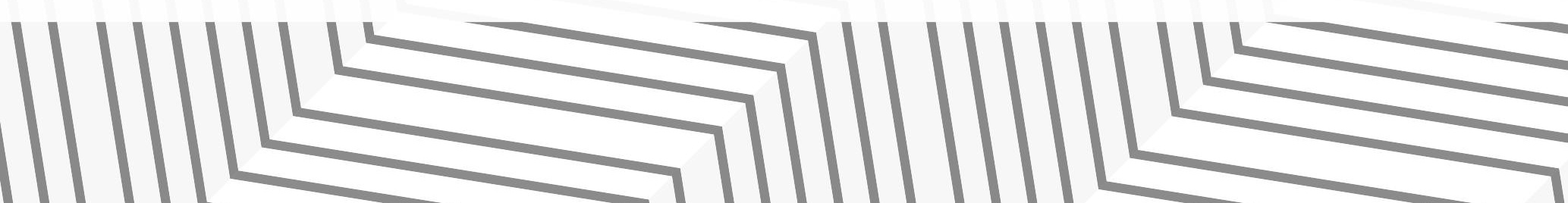





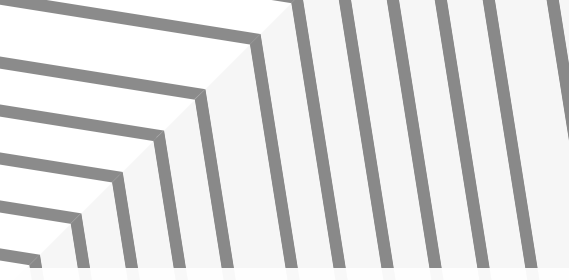

\section{MESAS DE DEBATE}

\section{MESA I - DAS PARTES E COMPETÊNCIA}

Objetivo:

Estabelecer quem pode utilizar o Ombudsman e o seu campo de atuação.

Coordenador:

Carlos Eduardo Richinitti | Desembargador do Tribunal de Justiça do Estado do Rio Grande do Sul

Integrantes:

Ricardo Morishita | Diretor de Pesquisas e Projetos no IDP

Antônio Pedro da Silva Machado | Diretor Jurídico do BACEN - Banco do Brasil e FEBRABAN

Aloisio Tupinambá | Ouvidor do BACEN

Marcio Guimarães | Promotor de Justiça no Rio de Janeiro

Maria Lucia Ettore | Superintendente de Ouvidoria

Recomenda-se:

- Incluir de um parágrafo único no artigo $2^{\circ}$ que contemple cláusula geral com a seguinte relação: "As disposições desse normativo não se sobrepõem, mas se harmonizam à legislação vigente, destacadamente ao Código de Defesa do Consumidor, às leis e normas especificamente direcionadas ao sistema bancários e à execução de atividades delegadas pelo setor público a instituições financeiras..

- Substituir, no artigo $2^{\circ}$ (e em todo texto normativo), a expressão "cliente" por "consumidor."

- Substituir, no artigo 13, a expressão "resolução" por "solução" de conflitos.

- Acrescentar no parágrafo $2^{\circ}$, do artigo 13, a ouvidoria, excluindo o SAC, por entendimento da maioria dos participantes da mesa.

- Acrescentar no parágrafo $2^{\circ}$, do artigo 14 , a ouvidoria da respectiva instituição financeira, por entendimento da maioria dos participantes da mesa.

- Substituir, no artigo 21, o termo "sentença" por "decisão".

- Acrescentar, no artigo 25, a instituição financeira signatária.

- Substituir, no artigo 27, a expressão "controvérsia" por "conflito."

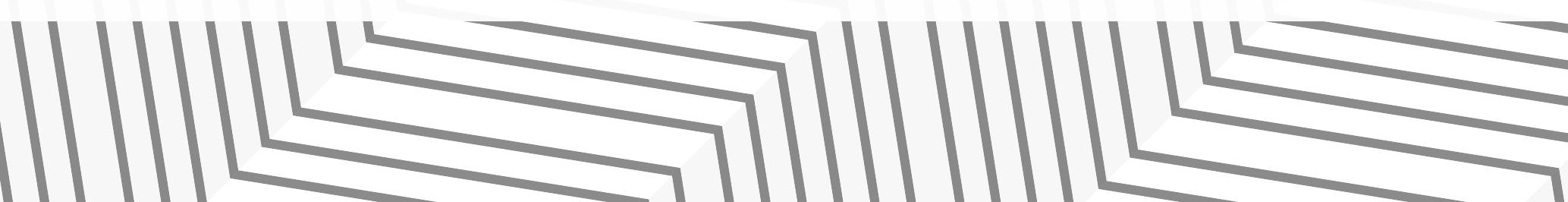



